\title{
Emerging therapies for right ventricular dysfunction and failure
}

\author{
Anna Klinke ${ }^{1} \wedge$, Torben Schubert ${ }^{1}$, Marion Müller ${ }^{1}$, Ekaterina Legchenko ${ }^{2}$, Jason G. E. Zelt ${ }^{3}$, \\ Tsukasa Shimauchi ${ }^{4}$, L. Christian Napp ${ }^{5}$, Alexander M. K. Rothman ${ }^{6}$, Sébastien Bonnet ${ }^{4}$, \\ Duncan J. Stewart ${ }^{3}$, Georg Hansmann ${ }^{2}$, Volker Rudolph ${ }^{1}$
}

${ }^{1}$ Clinic for General and Interventional Cardiology/Angiology, Herz- und Diabeteszentrum NRW, Ruhr-Universität Bochum, Bad Oeynhausen, Germany; ${ }^{2}$ Department of Pediatric Cardiology and Critical Care, Hannover Medical School, Hannover, Germany; ${ }^{3}$ Division of Cardiology, University of Ottawa Heart Institute and the Ottawa Hospital Research Institute, University of Ottawa, Ottawa, Canada; ${ }^{4}$ Pulmonary Hypertension Research Group, Centre de recherche de IUCPQ/Laval University, Quebec, Canada; ${ }^{5}$ Department of Cardiology and Angiology, Hannover Medical School, Hannover, Germany; ${ }^{6}$ University of Sheffield and Sheffield Teaching Hospitals NHS Trust, Sheffield, UK

Contributions: (I) Conception and design: A Klinke, G Hansmann, V Rudolph; (II) Administrative support: All authors; (III) Provision of study materials or patients: None; (IV) Collection and assembly of data: None; (V) Data analysis and interpretation: None; (VI) Manuscript writing: All authors; (VII) Final approval of manuscript: All authors.

Correspondence to: Anna Klinke, PhD. Clinic for General and Interventional Cardiology/Angiology, Herz- und Diabeteszentrum NRW, University Hospital, Ruhr Universität Bochum, Georgstrasse 11, 32545 Bad Oeynhausen, Germany. Email: aklinke@hdz-nrw.de.

\begin{abstract}
Therapeutic options for right ventricular (RV) dysfunction and failure are strongly limited. Right heart failure (RHF) has been mostly addressed in the context of pulmonary arterial hypertension $(\mathrm{PAH})$, where it is not possible to discern pulmonary vascular- and RV-directed effects of therapeutic approaches. In part, opposing pathomechanisms in RV and pulmonary vasculature, i.e., regarding apoptosis, angiogenesis and proliferation, complicate addressing RHF in PAH. Therapy effective for left heart failure is not applicable to RHF, e.g., inhibition of adrenoceptor signaling and of the renin-angiotensin system had no or only limited success. A number of experimental studies employing animal models for PAH or RV dysfunction or failure have identified beneficial effects of novel pharmacological agents, with most promising results obtained with modulators of metabolism and reactive oxygen species or inflammation, respectively. In addition, established $\mathrm{PAH}$ agents, in particular phosphodiesterase- 5 inhibitors and soluble guanylate cyclase stimulators, may directly address RV integrity. Promising results are furthermore derived with microRNA (miRNA) and long non-coding RNA (lncRNA) blocking or mimetic strategies, which can target microvascular rarefaction, inflammation, metabolism or fibrotic and hypertrophic remodeling in the dysfunctional RV. Likewise, pre-clinical data demonstrate that cell-based therapies using stem or progenitor cells have beneficial effects on the RV, mainly by improving the microvascular system, however clinical success will largely depend on delivery routes. A particular option for $\mathrm{PAH}$ is targeted denervation of the pulmonary vasculature, given the sympathetic overdrive in $\mathrm{PAH}$ patients. Finally, acute and durable mechanical circulatory support are available for the right heart, which however has been tested mostly in RHF with concomitant left heart disease. Here, we aim to review current pharmacological, RNA- and cell-based therapeutic options and their potential to directly target the RV and to review available data for pulmonary artery denervation and mechanical circulatory support.
\end{abstract}

Keywords: Right ventricle; right heart failure (RHF); pulmonary arterial hypertension (PAH); remodeling; right heart failure therapy

Submitted Jun 30, 2020. Accepted for publication Aug 27, 2020.

doi: $10.21037 / \mathrm{cdt}-20-592$

View this article at: http://dx.doi.org/10.21037/cdt-20-592

^ ORCID: 0000-0002-1118-4082. 


\section{Introduction}

Right ventricular (RV) dysfunction is associated with poor clinical outcomes (1) independent of the etiology (2). Yet, specific therapies that directly target right heart dysfunction are strongly limited. RV dysfunction and failure and its pharmacological therapy have been studied predominantly in the context of pulmonary arterial hypertension (PAH) $(3,4)$, and less commonly in left heart diseases $(5)$. Indeed, current clinical therapies for PAH mainly pursue a reduction of pressure overload via relaxation of the pulmonary vasculature (4), although some drugs appear to have additional anti-remodeling or anti-inflammatory effects. Whether therapies specifically targeting the RV provide substantial benefit compared to existing therapies (4) is unknown. Current heart failure treatment, which has been approved for and tested in patients with left heart failure (LHF), is less effective or in some instances even ineffective or harmful in the treatment of right heart failure (RHF), given the unique geometry, mechanics, metabolism, vascularity and response to pressure overload of the RV (6-9). The scope of this article is to summarize emerging therapies of RHF. We review established vasodilatory therapies for PAH with a distinct focus on their potential or confirmed direct RV effects. We also summarize novel, innovative pharmacological, cell-based and RNA-based strategies specifically addressing the RV. Finally, we address $\mathrm{RV}$-directed therapies in etiologies of RHF other than $\mathrm{PAH}$, thereby creating a new focus towards the RV in conditions dominated by failing left heart structures. RV dysfunction in the context of congenital heart disease (CHD) is covered elsewhere in this special issue (10). Moreover, the molecular mechanisms of RV dysfunction in PAH with a particular focus on the coronary vasculature, sex hormones, and glucose/lipid metabolism are reviewed elsewhere in this special issue (3).

\section{Non-approved pharmacotherapies}

\section{Potential of approved pulmonary vasodilator therapeutics to target the $R V$ myocardium}

In patients with $\mathrm{PAH}$ it is difficult to discriminate between vascular and myocardial effects of any therapy-the gold standard for distinction is invasive pressure-volume loop assessment. Meta-analyses of clinical data suggest that the direct impact of established PAH medications on the myocardium is limited $(11,12)$. In a number of trials phosphodiesterase-5 (PDE-5) inhibitors and endothelin receptor antagonists (ERAs) failed to be beneficial in patients with group 2 pulmonary hypertension $(\mathrm{PH})$, in particular with heart failure with preserved ejection fraction (HFpEF) (13-16) (for main clinical study findings see Table 1). In contrast, PDE-5 inhibitors, stimulators of soluble guanylate cyclase (sGC) and prostacyclin analogues appear to exert advantageous effects on RV myocardium in preclinical models (for schematic overview see Figure 1) (34-36). The experimental model of pulmonary artery banding (PAB),

Table 1 Main findings from clinical studies using pharmacotherapeutics with an emphasis on the RV

\begin{tabular}{|c|c|c|c|c|}
\hline Drug & $\begin{array}{l}\text { Mechanism of } \\
\text { action }\end{array}$ & Study design/patient cohort/reference & $\begin{array}{l}\text { Benefit on } \\
\text { (number of patients) }\end{array}$ & $\begin{array}{l}\text { No benefit on } \\
\text { (number of patients) }\end{array}$ \\
\hline \multicolumn{5}{|c|}{ Using approved PAH therapeutics } \\
\hline Macitentan & ETA & $\begin{array}{l}\text { Multicentre, placebo-controlled, randomized phase } \\
\text { II study/PH-LV dysfunction (16) }\end{array}$ & - & Hemodynamics $(n=60)$ \\
\hline \multirow[t]{3}{*}{ Sildenafil } & PDE5-inhibitor & $\begin{array}{l}\text { Multicentre, double-blind, placebo-controlled, } \\
\text { parallel-group, randomized clinical trial/HFpEF (13) }\end{array}$ & - & $\begin{array}{l}\text { Exercise capacity } \\
(\mathrm{n}=216)\end{array}$ \\
\hline & & $\begin{array}{l}\text { Single-centre randomized controlled } \\
\text { trial/HFpEF-PH (14) }\end{array}$ & - & $\begin{array}{l}\text { Exercise capacity, } \\
\text { hemodynamics }(n=52)\end{array}$ \\
\hline & & $\begin{array}{l}\text { Retrospective non-randomized study/RHF-LVAD } \\
\text { (17) }\end{array}$ & $\begin{array}{l}\text { Hemodynamics, RV } \\
\text { function }(n=14)\end{array}$ & - \\
\hline
\end{tabular}

Table 1 (continued) 
Table 1 (continued)

\begin{tabular}{|c|c|c|c|c|}
\hline Drug & $\begin{array}{l}\text { Mechanism of } \\
\text { action }\end{array}$ & Study design/patient cohort (reference) & $\begin{array}{l}\text { Benefit on } \\
\text { (number of patients) }\end{array}$ & $\begin{array}{l}\text { No benefit on } \\
\text { (number of patients) }\end{array}$ \\
\hline \multicolumn{5}{|c|}{ Targeting adrenoceptors } \\
\hline Carvedilol & $\beta 1-\mathrm{RA}, \alpha 1-\mathrm{RA}$ & Single-arm open-label pilot study/PAH (18) & RV function $(n=6)$ & - \\
\hline \multirow[t]{2}{*}{ Bisoprolol } & \multirow[t]{2}{*}{$\beta 1-\mathrm{RA}$} & $\begin{array}{l}\text { Single-centre, randomized, placebo-controlled, } \\
\text { crossover trial/PAH (20) }\end{array}$ & - & $\begin{array}{l}\text { Exercise capacity, RV } \\
\text { function }(n=16)\end{array}$ \\
\hline & & $\begin{array}{l}\text { Randomized, placebo-controlled, double blind, } \\
\text { cross-over study/PAH (21) }\end{array}$ & - & RV function $(n=18)$ \\
\hline Spironolactone & $\begin{array}{l}\text { Mineralo- } \\
\text { corticoid-RA }\end{array}$ & $\begin{array}{l}\text { Randomized, double-blind, placebo-controlled } \\
\text { trial/PAH (22) }\end{array}$ & - & $\begin{array}{l}\text { Exercise capacity } \\
(\mathrm{n}=199)\end{array}$ \\
\hline \multirow[t]{2}{*}{ Captopril } & \multirow[t]{2}{*}{ ACE inhibitor } & Observational study/PH (23) & - & Hemodynamics $(n=4)$ \\
\hline & & Observational study/PH (24) & - & Hemodynamics $(n=7)$ \\
\hline \multicolumn{5}{|c|}{ Targeting energy metabolism } \\
\hline Dichloroacetate & PDK inhibitor & Open-label study/PAH (25) & $\begin{array}{l}\text { Hemodynamics, RV } \\
\text { function }(n=16)\end{array}$ & - \\
\hline Ranolazine & \multicolumn{2}{|c|}{$\begin{array}{l}\text { Sodium current and Prospective, open-label pilot study/PAH (26) } \\
\text { partial FAO inhibitor }\end{array}$} & $\begin{array}{l}\text { Hemodynamics, RV } \\
\text { function, exercise } \\
\text { capacity }(n=11)\end{array}$ & - \\
\hline Anakinra & IL-1-RA & $\begin{array}{l}\text { Single-group, open-label phase IB/II pilot } \\
\text { study/PAH (29) }\end{array}$ & HF symptoms $(n=6)$ & $\begin{array}{l}\text { Exercise capacity, RV } \\
\text { function }(n=6)\end{array}$ \\
\hline Selonsertib & ASK1 inhibitor & $\begin{array}{l}\text { Phase II, dose-ranging, randomized, double-blind, } \\
\text { placebo-controlled/PAH (30) }\end{array}$ & - & $\begin{array}{l}\text { Hemodynamics } \\
(\mathrm{n}=150)\end{array}$ \\
\hline rhACE2 & rhACE2 & Open-label pilot study/PAH (31) & Hemodynamics $(n=5)$ & - \\
\hline \multicolumn{5}{|c|}{ Targeting tyrosine kinases } \\
\hline \multirow[t]{2}{*}{ Imatinib } & TKI & $\begin{array}{l}\text { Randomized, double-blind, placebo-controlled } \\
\text { pilot study/PAH (32) }\end{array}$ & Hemodynamics $(n=42)$ & $\begin{array}{l}\text { Exercise capacity, } \\
\text { hemodynamics (mPAP) } \\
(\mathrm{n}=42)\end{array}$ \\
\hline & & $\begin{array}{l}\text { Observational study (in combination with } \\
\text { bosentan, iloprost and sildenafil)/PAH (33) }\end{array}$ & $\begin{array}{l}\text { Hemodynamics, } \\
\text { exercise capacity }(n=1)\end{array}$ & - \\
\hline
\end{tabular}

ACE, angiotensin converting enzyme; ASK1, apoptosis signal-regulating kinase 1; FAO, fatty acid oxidation; ETA, endothelin-1 receptor antagonist; HF, heart failure; IL, interleukin; mPAP, mean pulmonary arterial pressure; PAH, pulmonary arterial hypertension; PDE, phosphodiesterase; PDK, pyruvate dehydrogenase kinase; $\mathrm{PH}$, pulmonary hypertension; RA, receptor antagonist; rh, recombinant human; $\mathrm{RV}$, right ventricle; TKI, tyrosine kinase inhibitor. 


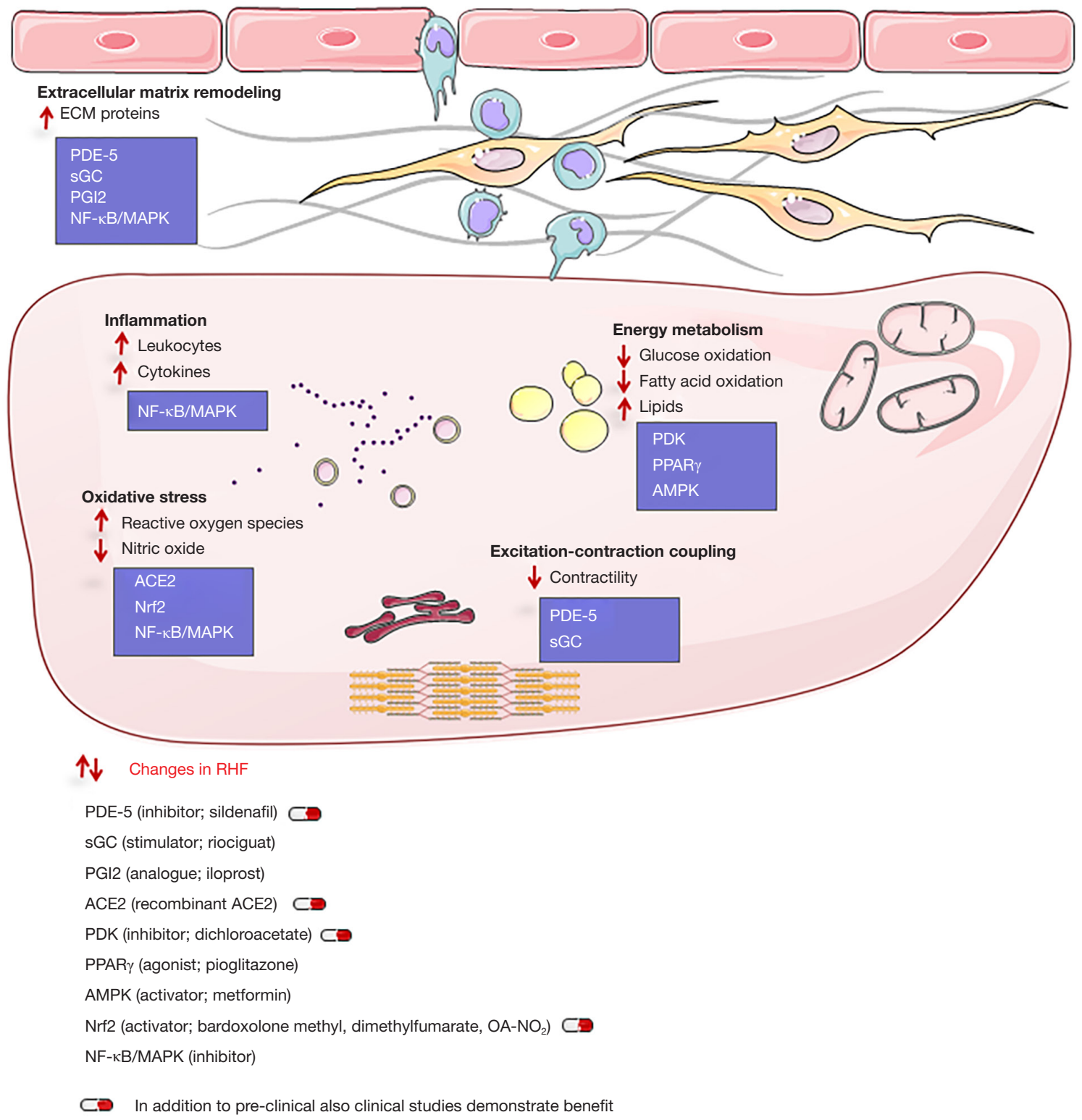

Figure 1 Scheme demonstrating main points of action of pharmacotherapeutics directly targeting RV myocardium in RHF. Key mechanisms of action and corresponding main drugs are given. ACE2, angiotensin converting enzyme 2; AMPK, 5'-adenosine monophosphate-activated protein kinase; ECM, extracellular matrix proteins; MAPK, mitogen-activated protein kinase; NF- $\kappa$, nuclear factor kappa-light-chainenhancer of activated B-cells; Nrf2, nuclear factor erythroid 2-related factor 2; PDE, phosphodiesterase; PDK, pyruvate dehydrogenase kinase; PGI2, prostacyclin; PPAR, peroxisome proliferator-activated receptor; sGC, soluble guanylate cyclase. This figure was created using Servier Medical Art templates, which are licensed under a Creative Commons Attribution 3.0 Unported License; https://smart.servier.com.

which induces RV pressure overload independently of pulmonary artery $(\mathrm{PA})$ remodeling, allows for investigation of RV-directed effects (37). In PAB models PDE-5 inhibition with sildenafil prevented RV dysfunction and reversed RV fibrotic remodeling $(34,36,38)$ (for experimental studies see Table 2). sGC stimulation with riociguat improved $\mathrm{RV}$ systolic function and reduced RV fibrosis without affecting RV hypertrophy (RVH) in PAB-exposed mice. Likewise, the prostacyclin analogue iloprost improved RV systolic function and exercise capacity, which was 
Table 2 Experimental pharmacological studies addressing RV dysfunction (indirectly, directly)

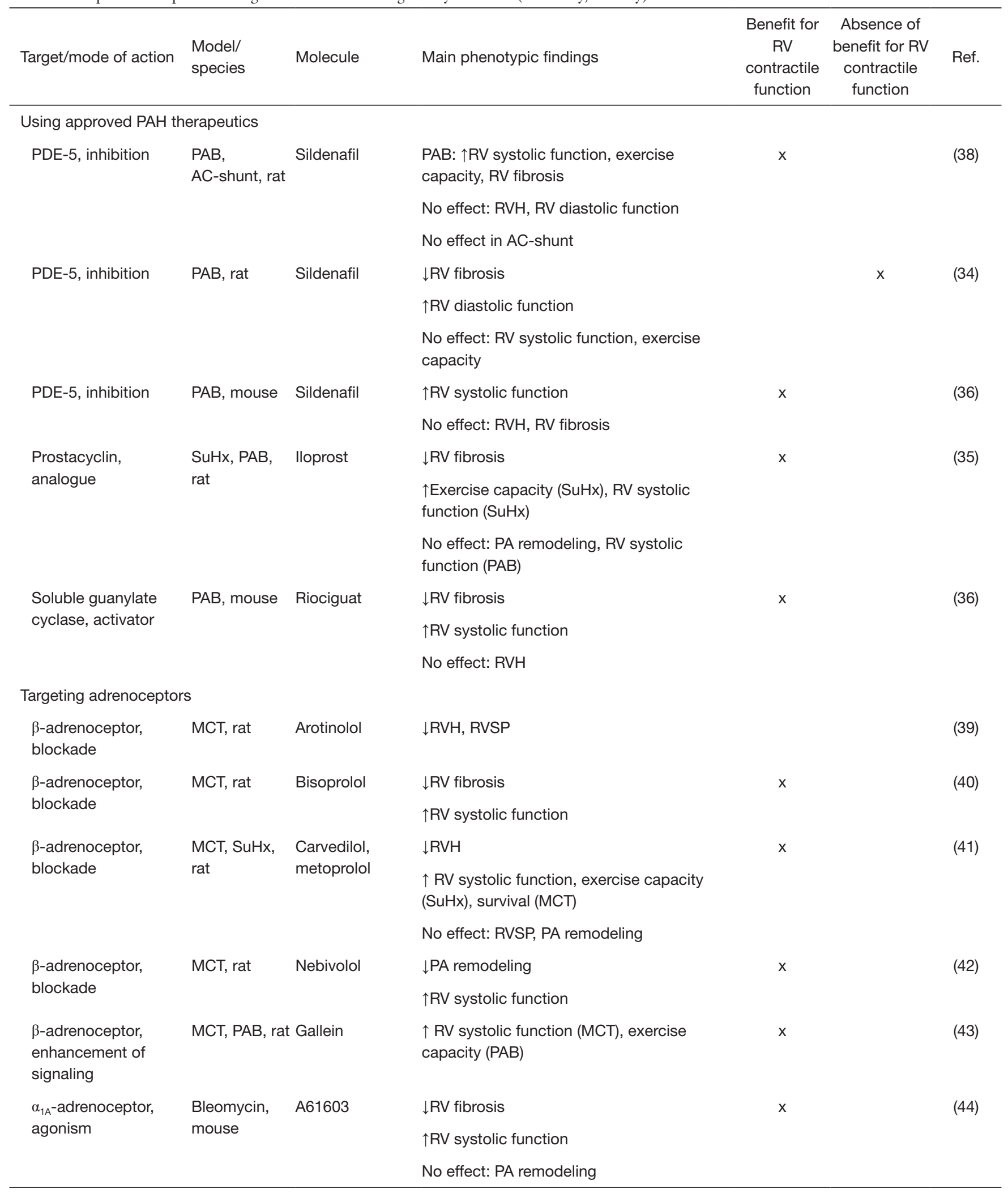

Table 2 (continued) 
Table 2 (continued)

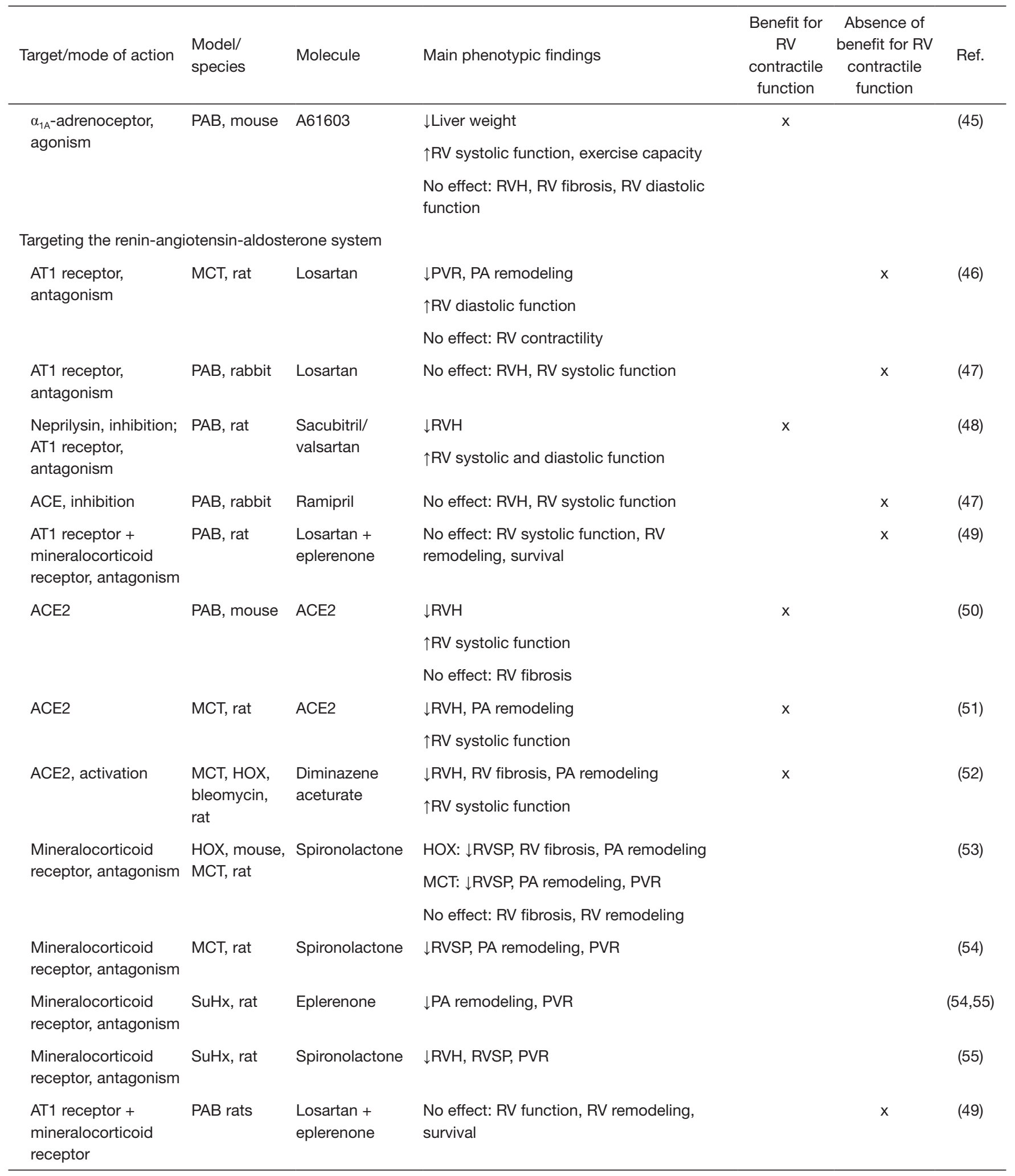

Table 2 (continued) 
Table 2 (continued)

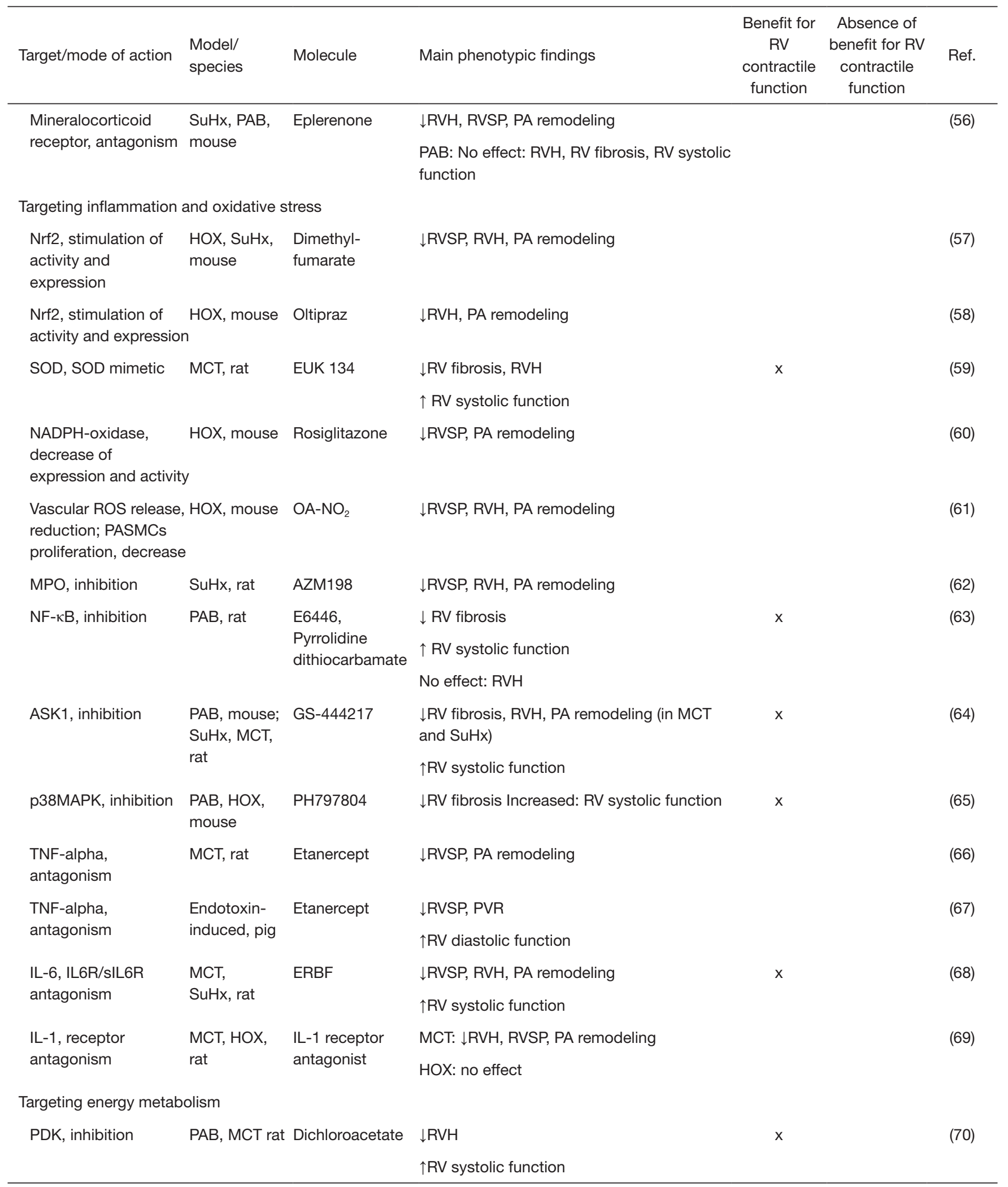

Table 2 (continued) 
Table 2 (continued)

\begin{tabular}{|c|c|c|c|c|c|c|}
\hline Target/mode of action & $\begin{array}{l}\text { Model/ } \\
\text { species }\end{array}$ & Molecule & Main phenotypic findings & $\begin{array}{l}\text { Benefit for } \\
\text { RV } \\
\text { contractile } \\
\text { function }\end{array}$ & $\begin{array}{l}\text { Absence of } \\
\text { benefit for RV } \\
\text { contractile } \\
\text { function }\end{array}$ & Ref. \\
\hline PDK, inhibition & HOX, rat & Dichloroacetate & $\begin{array}{l}\downarrow R V H, P V R, \text { RVSP, PA constriction and } \\
\text { remodeling } \\
\uparrow R V \text { CO }\end{array}$ & & & $(71)$ \\
\hline PDK, inhibition & $\begin{array}{l}\text { RV volume } \\
\text { overload, pig }\end{array}$ & Dichloroacetate & $\begin{array}{l}\downarrow R V H \\
\uparrow R V \text { contractile reserve }\end{array}$ & $x$ & & (73) \\
\hline FAO, partial inhibition & $\mathrm{PAB}$, rat & $\begin{array}{l}\text { Trimetazidine, } \\
\text { ranolazine }\end{array}$ & $\begin{array}{l}\downarrow R V H, \text { RV fibrosis } \\
\uparrow R V \text { systolic function, exercise capacity }\end{array}$ & $x$ & & $(74)$ \\
\hline $\begin{array}{l}\text { RV lipid deposition, } \\
\text { reduction }\end{array}$ & $\begin{array}{l}\text { Western diet } \\
+ \text { PAB, mouse }\end{array}$ & Metformin & $\begin{array}{l}\downarrow R V S P, R V H \\
\uparrow R V \text { diastolic function }\end{array}$ & & $x$ & $(77)$ \\
\hline $\begin{array}{l}\text { PPAR } \gamma \text { activation, } \\
\text { reduction of RV } \\
\text { intramyocardial lipid } \\
\text { deposition }\end{array}$ & SuHx, rat & Pioglitazone & $\begin{array}{l}\downarrow R V S P, \text { RVEDP, RVH, RV fibrosis, PA } \\
\text { remodeling } \\
\uparrow R V \text { systolic function, RV diastolic function }\end{array}$ & $x$ & & $(78)$ \\
\hline PPAR $\gamma$, activation & $\begin{array}{l}\text { ApoE-ko + } \\
\text { HFD, mouse }\end{array}$ & Rosiglitazone & $\downarrow R V S P, R V H, P A$ remodeling & & $x$ & (79) \\
\hline \multicolumn{7}{|c|}{ Targeting extracellular matrix remodeling } \\
\hline Galectin-3, inhibition & PAB, mouse & $\begin{array}{l}\mathrm{N}- \\
\text { acetyllactosamine }\end{array}$ & $\begin{array}{l}\downarrow R V \text { fibrosis } \\
\text { No effect: RV systolic function }\end{array}$ & & $x$ & (83) \\
\hline \multicolumn{7}{|l|}{ Targeting HDACs } \\
\hline $\begin{array}{l}\text { HDAC class I, II, IV, } \\
\text { inhibition }\end{array}$ & HOX, rat & $\begin{array}{l}\text { Valproic acid, } \\
\text { suberoylanilide }\end{array}$ & $\downarrow R V H$, RVSP, PA remodeling & & & (84) \\
\hline $\begin{array}{l}\text { HDAC class I, } \\
\text { inhibition }\end{array}$ & HOX, rat & MGCD0103 & $\begin{array}{l}\downarrow R V S P, \text { PA remodeling } \\
\text { No effect: RV systolic function }\end{array}$ & & $x$ & $(85)$ \\
\hline $\begin{array}{l}\text { HDAC class I, II, } \\
\text { inhibition }\end{array}$ & $\mathrm{PAB}$, rat & $\begin{array}{l}\text { Trichostatin A, } \\
\text { valproic acid }\end{array}$ & $\begin{array}{l}\downarrow R V \text { systolic function } \\
\uparrow R V \text { fibrosis }\end{array}$ & & & $(86)$ \\
\hline
\end{tabular}

Table 2 (continued) 
Table 2 (continued)

\begin{tabular}{|c|c|c|c|c|c|c|}
\hline Target/mode of action & $\begin{array}{l}\text { Model/ } \\
\text { species }\end{array}$ & Molecule & Main phenotypic findings & $\begin{array}{l}\text { Benefit for } \\
\text { RV } \\
\text { contractile } \\
\text { function }\end{array}$ & $\begin{array}{l}\text { Absence of } \\
\text { benefit for RV } \\
\text { contractile } \\
\text { function }\end{array}$ & Ref. \\
\hline $\begin{array}{l}\text { HDAC class I, } \\
\text { inhibition }\end{array}$ & $\mathrm{MCT}$, rat & Valproic acid & $\downarrow P A$ remodeling, $\mathrm{RVH}$ & & & $(87)$ \\
\hline $\begin{array}{l}\text { HDAC class VI, } \\
\text { inhibition }\end{array}$ & $\begin{array}{l}\text { SuHx, MCT, } \\
\text { rat }\end{array}$ & Tubastatin A & $\downarrow$ PA remodeling, RVH, RVSP, PVR & & & $(89)$ \\
\hline
\end{tabular}

surprisingly not associated with a reduction of PA pressure and RVH in the Sugen5416/hypoxia ( $\mathrm{SuHx}$ ) rat model for PAH. Rather, it was accompanied by a marked reduction of RV fibrosis, as it was seen also in PAB-exposed rats (35). These discrepant findings underline the difficulties in translating PAH medications to treatment of RHF originating from conditions other than PAH. Recently, sildenafil administration was evaluated for prevention of acute RHF following implantation of left ventricular assist device (LVAD). LVAD implantation is an important strategy in patients with end-stage LHF, however, in $4 \%$ to $50 \%$ of cases RHF occurs early after implantation and significantly increases mortality (90). Sildenafil is frequently used off-label to treat and/or prevent RHF post LVAD implantation (91). However, a recently published analysis from the INTERMACS (Interagency Registry for Mechanically Assisted Circulatory Support) registry uncovered that the incidence of RHF and the relative risk of bleeding was markedly increased with sildenafil therapy compared to controls (17). These disappointing results question the benefit of PA vasodilators for LVAD recipients (clinical trial using sildenafil: NCT03356353) (for ongoing clinical trials, see Table 3). Other clinical studies will investigate the ERA macitentan for treatment of $\mathrm{PH}$ following LVAD implantation (NCT02554903), and the inotropic agents levosimendan (a calcium sensitizer) (NCT03659851) or milrinone (a PDE-3 inhibitor) (NCT03217331) as pretreatment before LVAD implantation. Given that both milrinone and levosimendan have additional PA vasodilating properties, they might be particularly well suited. Levosimendan was effective to restore RV-PA coupling in an experimental model of acute pressure overload (92) and is currently tested also in patients with $\mathrm{HFpEF}$-associated PH (NCT03541603, NCT03624010).

Further preclinical studies and careful evaluation of clinical data are required to follow up on the discrepancies of experimental and clinical studies, on the promising preclinical results and to unravel potential molecular mechanisms that may directly target RV dysfunction.

\section{Neurobormonal modulation}

\section{Beta-adrenoceptor antagonists}

Use of beta-adrenoceptor antagonists ( $\beta$-blocker) is an essential component of LHF therapy. In contrast, it is not clear whether $\beta$-blocker provide benefit for RHF, although at least for RHF secondary to PAH it is known that neurohormonal activation is high (93). Currently, $\beta$-blocker application is not recommended for PAH due to their negative inotropic and chronotropic effects. Clinical studies on the use of $\beta$-blockers in PAH had inconsistent results dependent on whether the $\beta 1$-selective bisoprolol $(20,21)$, or $\beta 1$ - and $\alpha 1$-blockade (carvedilol) was employed. Carvedilol was safe in PAH patients and even normalized pathologically increased RV glucose uptake in PAH (18). However, whereas it improved RV function and exercise capacity in small studies with PAH or RV dysfunction of other origin than PAH $(19,94)$, no benefit on hemodynamics or exercise capacity was observed in a larger PAH study (18) (Table 1). Small clinical trials are ongoing for PAH (NCT02507011, NCT00240656) (Table 3). In preclinical PAH models encouraging results have been 



ホ
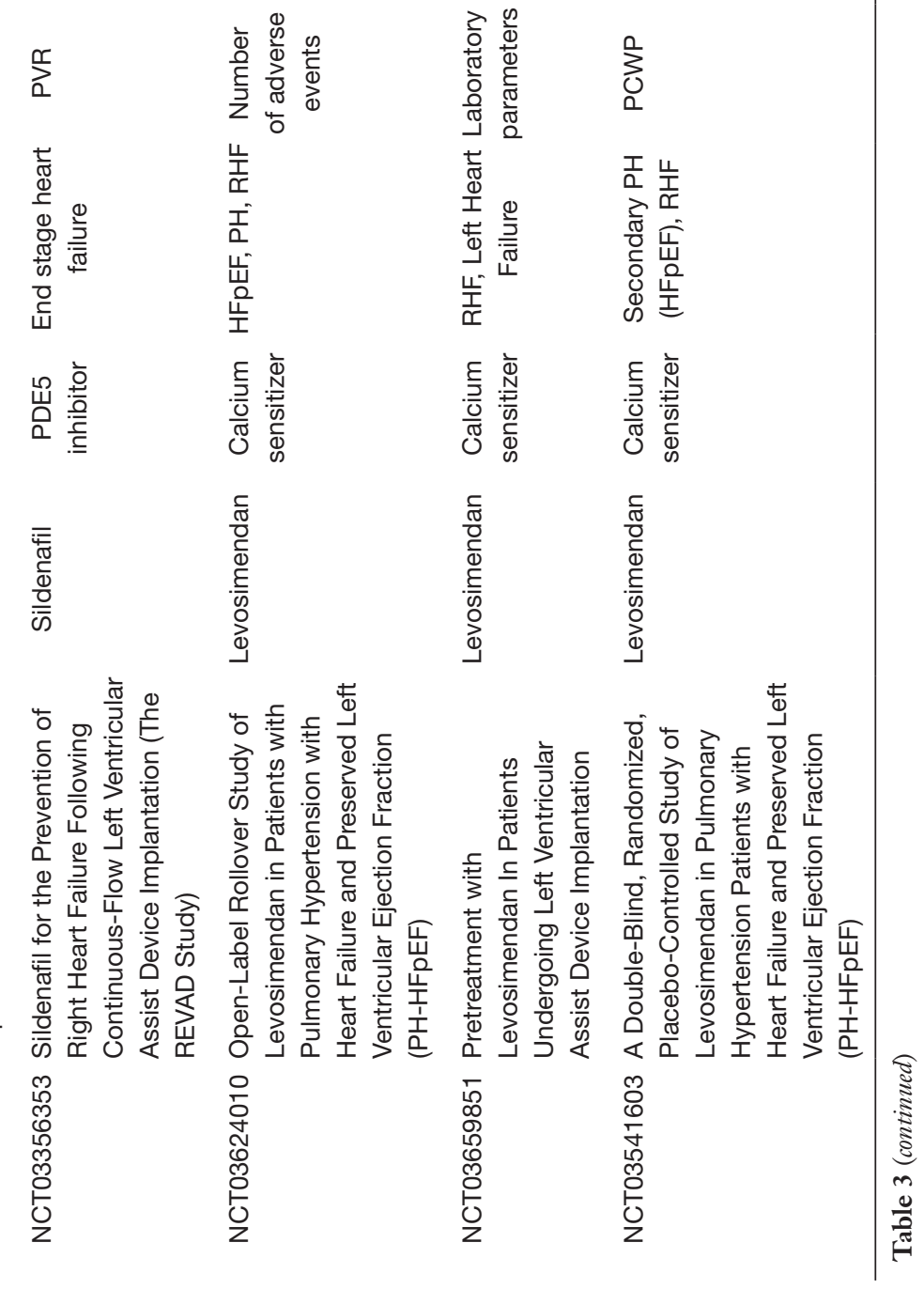


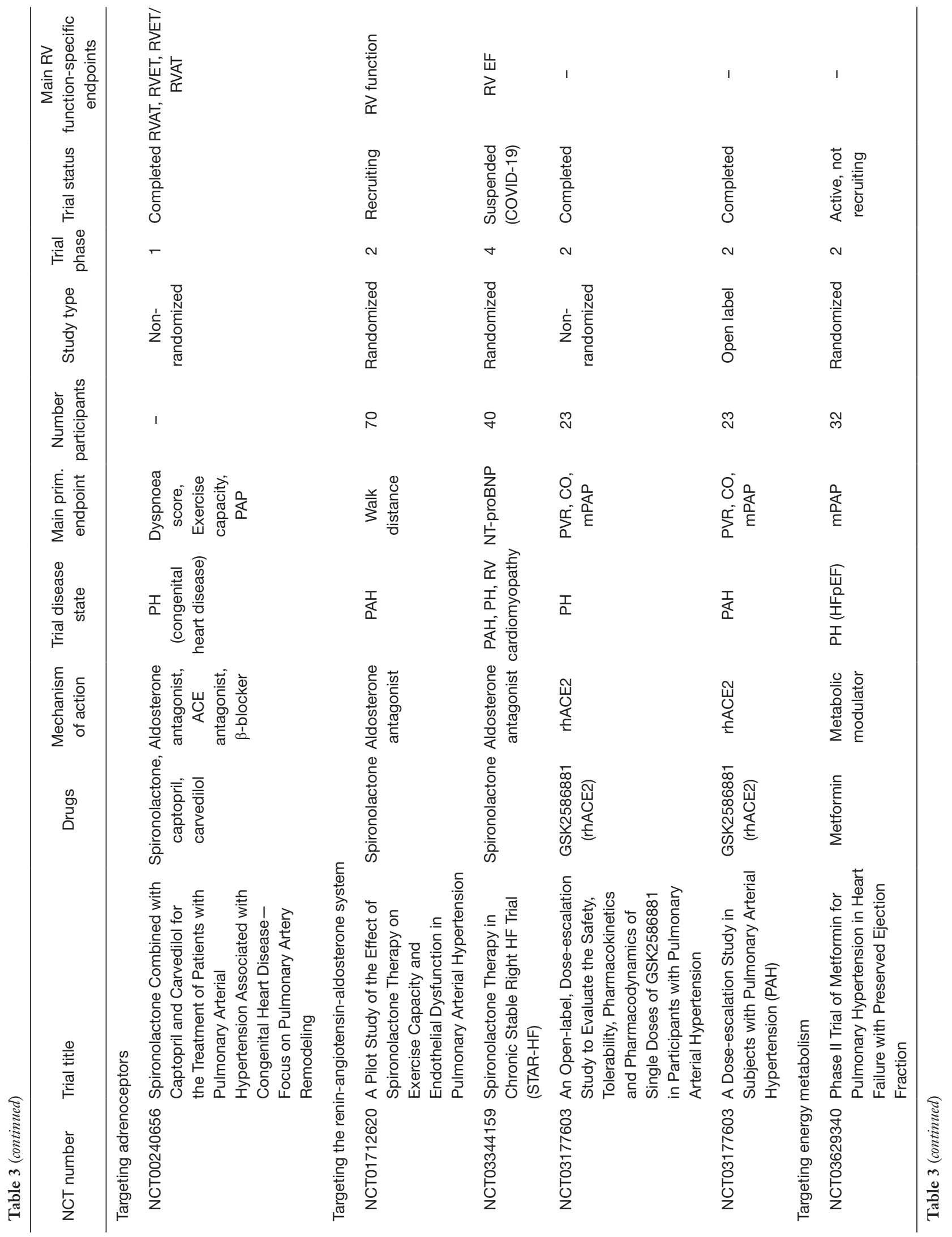




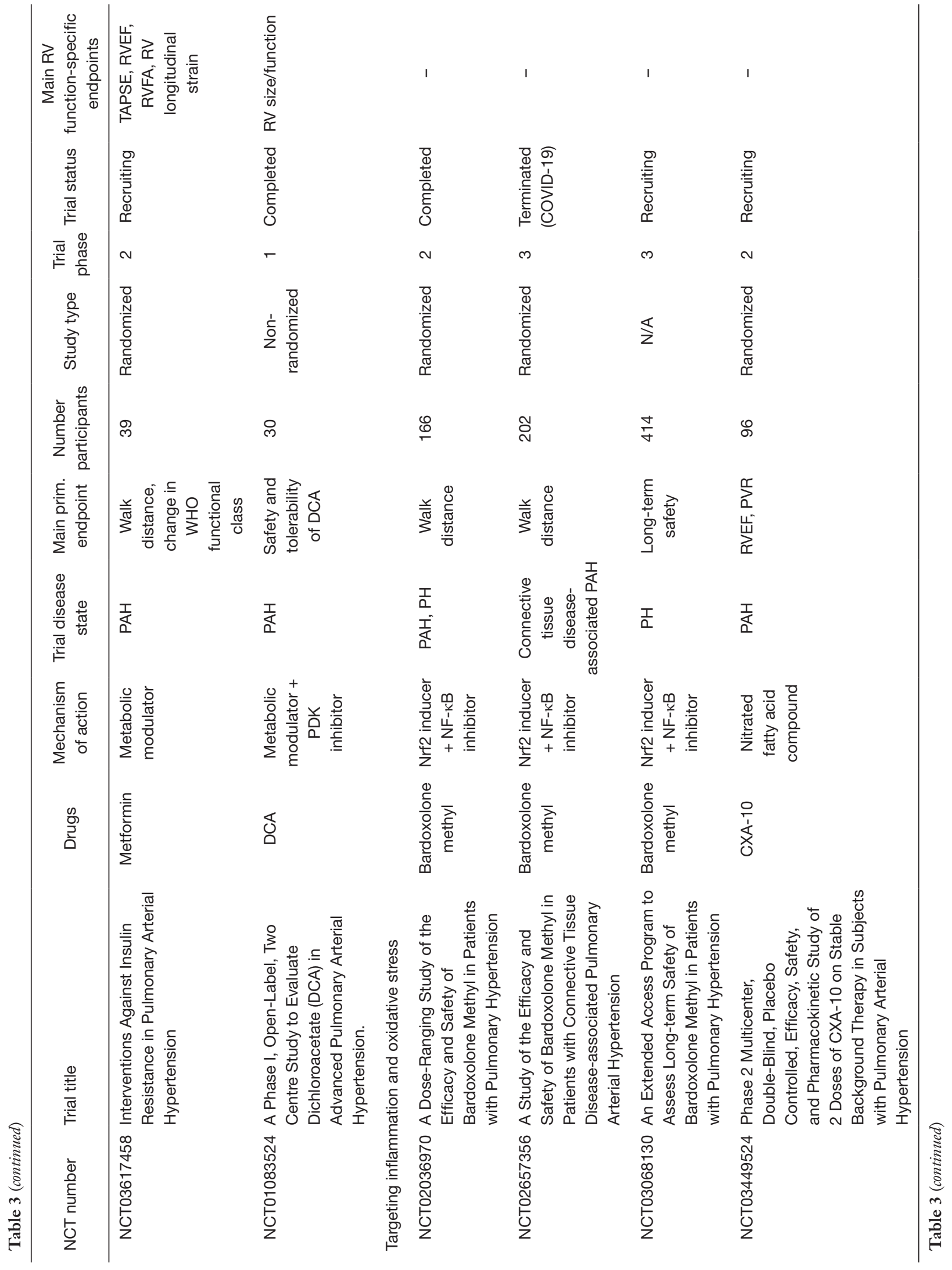




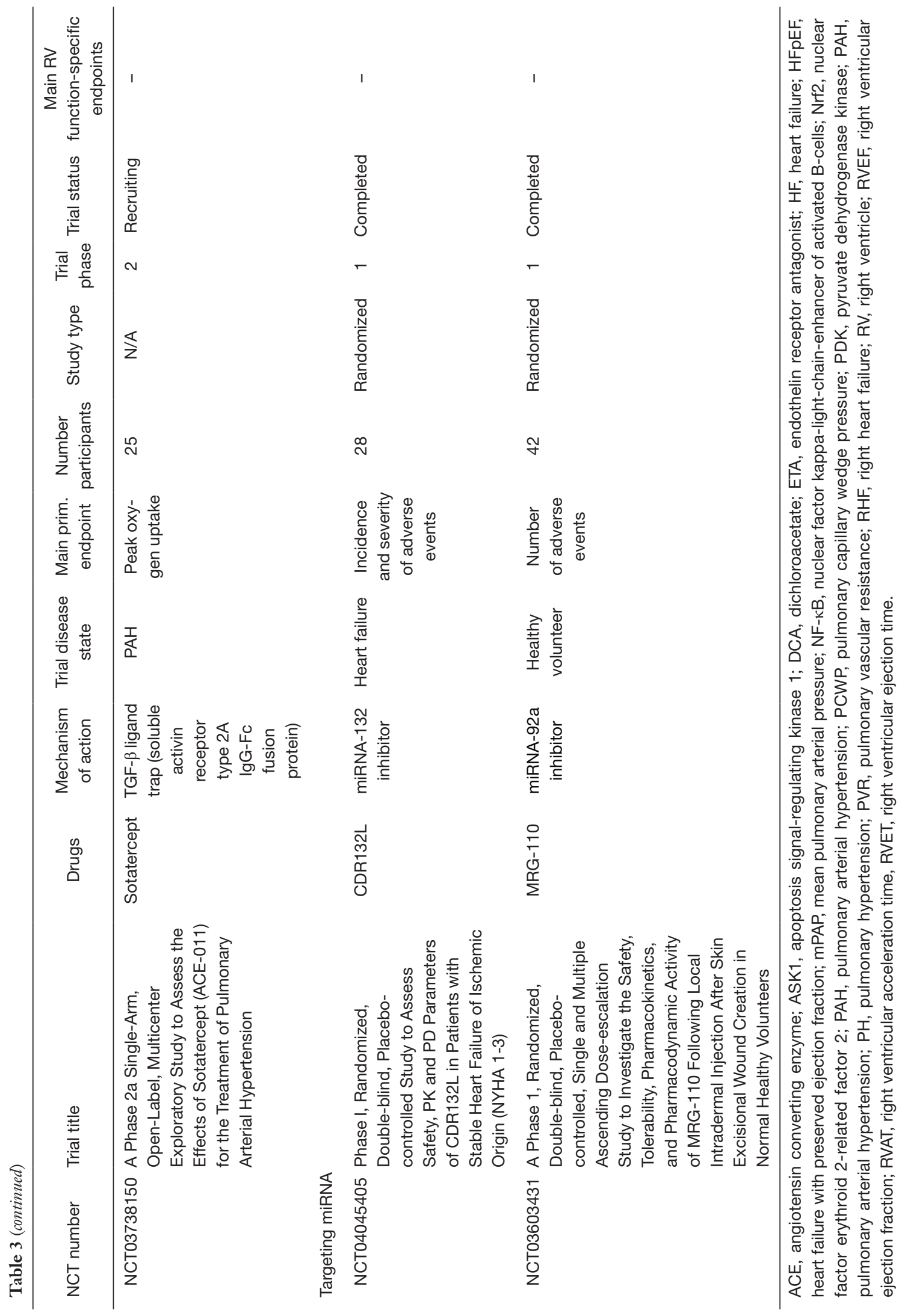


obtained: $\beta$-blockade applied in monocrotaline (MCT) and SuHx rat models was associated with reduction of RV dysfunction, RV fibrosis and RV inflammation (39-42) (Table 1). However, contrasting data suggest that reinforcement of $\beta$-adrenoceptor signaling improved RV function in the MCT rat model (43). Interestingly, agonism on the $\alpha 1 \mathrm{~A}$-adrenoceptor prevented and reversed RHF in experimental mouse models of bleomycin- and PABinduced RV failure $(44,45,95)$ (Table 2). Here, improved $\mathrm{RV}$ function was linked to increased myofilament force development and associated with markedly diminished levels of reactive oxygen species (ROS) in the RV.

\section{Modulation of the renin-angiotensin-aldosterone system (RAAS)}

As it is the case for adrenoceptor blockade, modulation of the RAAS is essential in LHF therapy, but its benefit for RHF remains elusive. The vasoconstrictive, pro-fibrotic and pro-inflammatory properties of angiotensin II (AngII) render this pathway attractive also for RHF therapy, and in PAH RAAS is clearly activated (46). Nevertheless, in experimental studies the AngII type 1 (AT1)-receptor blocker losartan had no beneficial effect on the RV $(47,49)$ (Table 2). Interestingly, a recent study suggested that the combination of AT1-receptor blockade with neprilysin inhibition (sacubitril/valsartan), which is successful in LHF therapy, improved RV function by attenuating adverse myocardial remodeling in $\mathrm{PAB}$-exposed rats (48). Inhibition of the angiotensin-converting enzyme (ACE) was rather disappointing in small PAH patient cohorts $(23,24)$ (Table 1).

More promising findings suggest to target ACE2, which converts AngI and AngII to Ang 1-7, Ang 1-9 and Ang 1-5, exerting vasodilating and anti-inflammatory effects via the Mas receptor $(96,97)$. Application of recombinant ACE2 protein or activation of ACE2 in PAH models reduced PA and $\mathrm{RV}$ remodeling and improved $\mathrm{RV}$ function $(51,52)$. Of note, improved RV function was also observed in the $\mathrm{PAB}$ model, suggesting a direct protective effect on RV myocardium (50). The current findings point towards the fact that the mechanism of action is rather related to anti-inflammatory and anti-oxidative actions than directly reducing AngII-dependent effects (98) (Figure 1). However, a single intravenous dose of ACE2 in PAH patients reduced pulmonary vascular resistance (PVR) and increased cardiac output (CO) (31). A phase 2 clinical trial proved good tolerability of recombinant ACE2 in patients with acute respiratory distress syndrome (99), and another phase 2 trial with PAH patients was completed recently (NCT03177603). It needs to be considered that ACE2 serves as a receptor for coronavirus SARS-CoV2 and facilitates cell entry potentially not only to alveolar cells, but also to cardiomyocytes (100). ACE2 expression is augmented on cardiomyocytes in patients with cardiac disease, which might increase risk for cardiac complications associated with Coronavirus Disease 2019 (COVID-19) (100).

Most consistent results are derived from studies on mineralocorticoid-receptor blockade, which indicate that blocking the aldosterone receptor exerts potent effects on PA remodeling. Those are related to a decrease of PA fibrosis, increase of nitric oxide (NO) bioavailability and inhibition of proliferation of pulmonary artery smooth muscle cells (PASMCs), but the RV is not directly affected. Thus, PA remodeling and PVR and in some studies also RVH were diminished by spironolactone or eplerenone in PAH models (53-56). In contrast, no effects on RV remodeling or function were observed in PAB models $(49,56)$ (Table 2). In a retrospective analysis spironolactone improved exercise capacity, brain natriuretic peptide (BNP) levels and New York Heart Association (NYHA) class in PAH patients (22). Ongoing clinical trials will further investigate the therapeutic potential of spironolactone and its modulation of vascular dysfunction for PAH patients (NCT01712620, NCT03344159) (Table 3).

\section{Metabolic regulators}

Metabolic remodeling is an important component of heart failure pathogenesis. As described in more detail by Agrawal and colleagues (3), due to reduced oxygen availability but also triggered by processes like inflammation and increased oxidative stress, substrate flexibility of cardiomyocytes is impaired. The mechanisms of metabolic dysregulation are not yet fully understood. In healthy myocardium, fatty acid oxidation (FAO) serves to about $70 \%$ for energy generation, and energy yield per molecule is higher than from glucose oxidation (GO), but on the other hand oxygen consumption is higher per molecule substrate. In dysfunctional cardiomyocytes, complete oxidative phosphorylation (OXPHOS) all the way through the citrate cycle (Krebs cycle) and electron transport chain (ETC, for efficient ATP production) is decreased and glycolysis is enhanced, resulting in reduced ATP generation (101). Pressure-overloaded hearts with pathological hypertrophy (RVH or LVH) revert to a fetal transcriptional and metabolic program, with increased utilization of glucose and reduced oxidative capacity (102). An important driver 
of the so-called Warburg effect, i.e., predominant glycolysis despite the presence of oxygen to generate ATP, is increased activity and expression of pyruvate dehydrogenase kinase (PDK), which inhibits pyruvate dehydrogenase (PDH). The Warburg effect does not only occur in the dysfunctional or failing RV (103) but also in the pulmonary vasculature (104), with the consequence of increased proliferation of PASMCs and fibroblasts.

\section{PDK inhibition}

The PDK inhibitor dichloroacetate (DCA) has successfully been employed in preclinical models and patients. Improvement of $\mathrm{RV}$ function in line with increase in $\mathrm{GO}$ was shown in PAB and MCT rat models (70) and in a large animal model of RV volume overload (73) (Table 2). Importantly, the advantageous effects of DCA are not only related to improved substrate utilization. It also restores the expression of voltage-gated potassium channels $\mathrm{Kv} 1.2, \mathrm{Kv} 1.5, \mathrm{Kv} 2.1$ and $\mathrm{Kv} 4.2$ in PASMCs and in RV cardiomyocytes. In PASMCs this leads to preserved membrane potential and diminished vasoconstriction in hypoxia (HOX) (71) and MCT rat models (72). Restoration of potassium channel expression also affects RV cardiomyocyte repolarization (70). However, it is important to note that genetic polymorphisms can influence DCA efficacy. This was demonstrated by a recent 4-month openlabel trial with 20 PAH patients. Here, DCA reduced PVR and increased exercise capacity, and this effect was more pronounced in individuals with absent or low polymorphism scores for the proteins sirtuin 3 and uncoupling protein 2, which regulate mitochondrial function in a PDK-dependent manner (25).

\section{Partial FAO inhibition}

FAO is in reciprocal relationship with GO, thus, partial inhibition of FAO is an oxygen-sparing mechanism, which renders the partial FAO inhibitors ranolazine and trimetazidine useful as anti-anginal drugs. Both have successfully been used to treat LHF (105-108), whereas the effects of ranolazine are also related to inhibition of late sodium current, thereby preventing sodium-dependent calcium overload (107). However, preclinical effects of trimetazidine and ranolazine in animal models of PAH/ RV dysfunction have been small $(74,75,109)$ (Table 2) and the results of the first clinical studies with trimetazidine have not been published or were negative $(110,111)$. In patients with $\mathrm{PAH}$, ranolazine had no effects in a small study (27), but significantly improved exercise capacity and
RV function in another small PAH study (26) (Table 1). It remains elusive whether these effects were attributed to metabolic modulation or sodium channel inhibition. Several clinical trials for ranolazine in $\mathrm{PH}$ particularly focusing on RV function are ongoing (NCT02829034, NCT01839110, NCT03273387) (Table 3). Importantly, FAO is naturally downregulated in dysfunctional myocardium, which amongst others leads to lipid accumulation in cardiomyocytes with enhanced generation of toxic lipid metabolites and reduced ATP yield [for detailed review see (101)]. Furthermore, mitochondrial fragmentation occurs in response to cellular stress in PAH/RV pressure overload and induces a metabolic switch from FAO to GO in the heart. Reversing this "FAO-to-GO switch" and restoring normal cardiac metabolism are sufficient to preserve $\mathrm{LV}$ function despite mitochondrial fragmentation (112). The latter finding indicates that the switch in energy generation in the failing adult ventricle may be maladaptive and likely contributes to pathogenesis of heart failure. Thus, we doubt that the concept of blocking FAO in RV or LV failure with pressure overload improves systolic performance, but may even have detrimental effects (102).

\section{Master regulators of glucose and lipid metabolism}

A current approach to address metabolic homeostasis in the heart and the pulmonary vasculature is to target the peroxisome proliferator-activated receptor gamma (PPAR $\gamma$ ), which is a key modulator of glucose and lipid metabolism, including mitochondrial FAO, as recently reviewed $(3,113)$. PPAR $\gamma$ is a transcription factor of the nuclear receptor superfamily and is activated by thiazolidinediones (TZDs) or endogenous ligands at specific binding sites. Pioglitazone, which is approved for therapy of diabetes mellitus type 2, was demonstrated to have a better safety profile than rosiglitazone $(114,115)$. Interestingly, current established PAH medications, treprostinil and sildenafil exert their antiproliferative effects via PPAR $\gamma$ activation (113). In heart failure and PAH, the actions of TZDs can be attributed to a variety of mechanisms, however normalization of cardiac energy metabolism may be an important element. Intriguingly, cardiomyocyte-specific deletion of PPAR $\gamma$ in mice provoked LV and RV systolic dysfunction, which was accompanied by decreased mRNA expression of genes encoding for important mediators of FAO (78). Pioglitazone inhibited exaggerated RV glucose uptake in SuHx-treated rats and reduced RV intramyocardial lipid accumulation as a possible culprit for lipotoxicity and RV failure. Pioglitazone further prevented RV fibrosis and normalized RV 
cardiomyocyte mitochondrial structure and organization. This, together with attenuated PA remodeling accounted for marked reduction of RVH and normalization of RV function (Table 2, Figure 1). Interestingly, transcription of important FAO-regulating genes, including PPAR $\gamma$ itself, proved to be downregulated in $\mathrm{RV}$ cardiomyocytes of $\mathrm{PAH}$ patients and were upregulated by pioglitazone in isolated neonatal cardiomyocytes (78). Besides this robust signal for the therapeutic action of TZDs via a direct effect on myocardial energy metabolism, a variety of other studies identified beneficial effects in preclinical PAH models linked to anti-inflammatory, anti-proliferative, pro-apoptotic and vasodilatory effects. Deletion of PPAR $\gamma$ in SMCs led to the development of PAH in mice. It was unraveled that PPAR $\gamma$ is a downstream target of bone morphogenetic protein (BMP) receptor type-2 (BMPR2), which mediates inhibition of SMC proliferation (116). Several further studies demonstrated TZD-dependent benefits in experimental $\mathrm{PAH}$ due to attenuation of PA vasoconstriction and remodeling $(79-81,117)$. Importantly, since FAO also increases oxygen consumption while producing more ATP, therapeutic PPAR $\gamma$ activation may require sufficient oxygen supply to the myocardium. Thus, PPAR $\gamma$ activating agents may not be started in end-stage PAH with low $\mathrm{CO}$ and high end-diastolic ventricular filling pressures. In these situations, the failing RV may incrementally benefit from oxygen sparing therapeutic approaches at the expense of less efficient ATP production. Despite the robust evidence provided by preclinical studies, there are no ongoing clinical trials to investigate TZDs for RHF or PAH.

\section{Metformin}

Enhanced lipid accumulation has been detected in human RV tissue of patients (postmortem) and in mice with heritable PAH (76). In this study, lipid accumulation in the BMPR2 R899X transgenic mouse model of PAH could be diminished by application of the biguanide metformin, however RV function was not improved. Metformin impacts on energy metabolism via activation of 5'-adenosine monophosphate-activated protein kinase (AMPK). RV lipid accumulation was also reduced by metformin in a model of metabolic syndrome induced by Western diet, in which RV dysfunction was further exaggerated by PAB (77). Metformin reduced RVH and improved RV diastolic function. Other experimental studies related positive effects of metformin on the RV to alternative mechanisms. In HOX and MCT rat models, metformin reduced PA remodeling, which was due to stimulating endothelial $\mathrm{NO}$ synthase activity and inhibiting mitogen-activated protein kinases (MAPK) (118). Moreover, in the SuHx rat model attenuated PA remodeling was linked to an inhibition of aromatase transcription, resulting in decreased estrogen levels (119). A phase 2 clinical trial investigates the effect of metformin in PAH (NCT03617458) and HFpEF-associated PH (NCT03629340).

Taken together, metabolic dysregulation in right heart dysfunction and failure is a promising therapeutic target. Further studies to understand its significance for PAH and RHF, to unravel in particular the role of FAO in RV failure, and to find appropriate, safe and efficient drugs are indispensable.

\section{Inbibition of inflammation and oxidative stress}

Inflammation has been suggested as a mediator and potential therapeutic target in cardiovascular disease (CVD), however no anti-inflammatory therapy has been approved yet. The mostly low-grade and sterile inflammatory processes in CVD comprise activation of leukocytes and fibroblasts with release of cytokines and ROS. Recent results from the CANTOS trial have shown that antiinflammatory treatment using a neutralizing antibody to interleukin (IL)-1 $\beta$ reduced hospitalization for LHF (120). In patients with $\mathrm{PAH}$, levels of circulating inflammatory markers correlate with disease severity, symptom burden and survival (121-125). The majority of studies investigating the role of inflammation in PAH links it to adverse pulmonary vascular remodeling $(62,125,126)$. In contrast, the effects of inflammation and anti-inflammatory therapy on $\mathrm{RV}$ remodeling and function are less clear. It is known that modulated apoptosis, increased reactive fibrosis, disturbed metabolism with mitochondrial dysfunction, altered $\mathrm{Ca}^{2+}$ handling and dysintegrity of sarcomere proteins are sensitive to inflammation and ROS (126-128). A number of experimental studies investigating $\mathrm{RV}$ remodeling and dysfunction following PAB have described increased RV cytokine levels and/or leukocyte infiltration (125). Thus, anti-inflammatory and anti-oxidative therapy is a promising tool to target PA and RV remodeling (129).

\section{Blockade of cytokines and leukocyte enzymes}

One potential strategy is blocking certain cytokines or their receptors. Cytokines like IL-1 $\beta$, IL-6 and tumor necrosis factor- $\alpha(\mathrm{TNF}-\alpha)$ are not only released in models of and patients with $\mathrm{PAH}$, but their tissue levels also increased in $\mathrm{RV}$ myocardium following PAB in mice (130). IL-1 $\beta$ is a 
central mediator of the inflammasome, however antagonism of the IL-1 receptor by anakinra yielded inconsistent results in preclinical and clinical studies. Its administration to MCT-treated rats reduced PA remodeling, however it failed to exert any effects in the HOX model of PAH as tested in the same study (69) (Table 2). It has to be considered that IL- $1 \beta$ regulates transdifferentiation of fibroblasts to activated myofibroblasts and may attenuate fibrotic remodeling (131-133). In a recent small single-arm open label PAH study, 14 days treatment with anakinra reduced C-reactive protein levels and symptom burden, but RV function was not significantly changed (29) (Table 1).

TNF- $\alpha$ inhibition appears to exert effects on PA remodeling. The specific antagonist etanercept modified PA remodeling and reduced PA pressure in experimental PAH models $(66,67)$.

The IL-6 receptor (IL-6R) is another potential therapeutic target in PAH. IL-6R on the surface of PASMC serves as a survival factor, and IL-6R antagonism not only reduced PA remodeling but improved RV function in MCT and SuHx rat models (68). However, the monoclonal antibody tocilizumab failed to achieve a change in PVR in a phase 2 open-label proof-of-concept study with $\mathrm{PAH}$ patients (28).

An important source of ROS is the leukocyte enzyme myeloperoxidase (MPO), that has been linked to a variety of cardiovascular conditions (134). MPO levels were increased in lungs of PAH patients. Knockout or inhibition of MPO reduced RVH, PA pressure and remodeling in the MCT rat and HOX mouse PAH models (62).

\section{Targeting signaling mediators}

A promising concept is to target central intracellular signaling cascades. The transcription factor nuclear factor E2-related factor 2 ( Nrf2) induces anti-oxidative effects like increased expression of heme-oxygenase-1 (HO-1). HO-1- as well as Nrf2-deficient mice develop RV dilation and infarction or PA remodeling and $\mathrm{RVH}$, respectively, under hypoxic conditions $(58,135)$. Stimulation of Nrf2 and HO-1 expression with Protandim in the SuHx rat model of PAH attenuated RV fibrosis and capillary rarefaction and improved RV function, without changes in PA pressure or remodeling (136). Nrf2 stimulation with oltipraz showed protective effects on PA remodeling in the HOX mouse model (58). Nitro-fatty acids $\left(\mathrm{NO}_{2}-\mathrm{FA}\right)$, a group of molecules with anti-inflammatory and anti-oxidative properties, in part via induction of HO-1 expression (137), attenuated PA remodeling, RVH and fibrosis in the HOX mouse model (61). A current phase 2 multicenter clinical study explores $\mathrm{NO}_{2}$-FA in patients with PAH (NCT03449524). Other Nrf2-stimulating agents (dimethyl fumarate), a superoxide dismutase (SOD) mimetic, and the PPAR $\gamma$ receptor stimulator rosiglitazone all exert anti-oxidative effects and achieved benefit in preclinical PAH models $(57,59,60)$ (Table 2). The Nrf2 and HO-1 axis is thus a promising target to reinforce anti-inflammatory and anti-oxidative processes (Figure 1). The Nrf2 activator bardoxolone methyl significantly improved exercise capacity in $\mathrm{PAH}$ patients in a phase 2 trial (138) (NCT02036970), although it was associated with adverse cardiovascular events in patients with end stage chronic kidney disease. Two more clinical trials are ongoing (NCT03068130; NCT02657356) (Table 3).

Furthermore, studies demonstrating inhibition of tolllike receptor 9/nuclear factor kappa-light-chain-enhancer of activated B-cells (NF- $\mathrm{kB})$ signaling (63) and inhibition of apoptosis signal-regulating kinase (ASK) 1 and p38 MAPK activity in PAB models $(64,65)$ are in favor of blocking inflammatory pathways. However, a clinical study on ASK1 inhibition in PAH including 150 patients failed to reach its primary endpoint (NCT02234141) (30).

Overall, modulation of inflammation and oxidative stress is a promising strategy to target maladaptive $\mathrm{RV}$ remodeling as well as PA constriction and remodeling in PAH at the same time. Given that a certain level of ROS is required for adaptive cell signaling and homeostasis, and that inflammatory cascades are indispensable for intact immune defense, induction of anti-oxidative and anti-inflammatory cascades may be the most prospective and feasible concept.

\section{Modulation of extracellular matrix (ECM) remodeling}

Fibrotic remodeling with enhanced deposition of interstitial and perivascular collagen and transdifferentiation of fibroblasts to myofibroblasts is a hallmark of the pressure overloaded and dysfunctional RV. Fibrosis also occurs during adaptive remodeling, but is suggested to become maladaptive when the stressor like increased afterload persists. It leads to increased ventricular stiffness and susceptibility to arrhythmias. It is widely accepted that maladaptive fibrosis of the LV contributes to impaired systolic and diastolic function and is associated with increased morbidity and mortality (139). This is, however, less clear for the RV. Preclinical studies suggest that effective therapeutic approaches to alleviate PAH or RV dysfunction upon PAB most commonly go along with a reduction of RV fibrosis (140). In the PAB model this 
was the case with a p38MAPK inhibitor (65), a 5-HT2 receptor antagonist (141), the prostacyclin analogue iloprost (35), the antioxidant protandim (136) and an ASK1 inhibitor (64). p38MAPK and ASK1 inhibition attenuated cardiac fibroblast activation and improved RV systolic function. However, recent research has challenged the concept of a causal relationship between fibrosis and RV function. A recent study by Boehm and colleagues showed that in a reversible $\mathrm{PAB}$ mouse model RV fibrosis slowly reversed at a time point when RV function and hypertrophy were already fully normalized (142). A promising biomarker and therapeutic target for cardiac fibrosis is galectin-3, which was linked to the development of LHF and also mortality and RV dysfunction in patients with PAH (83). In the murine PAB model, galectin-3 knockout or inhibition and also the anti-fibrotic agent pirfenidone attenuated RV fibrosis, but did not significantly affect RV function (83).

\section{HDAC inbibitors}

There is growing interest in epigenetic mechanisms in CVD. An important element of epigenetic regulation is histone acetylation, controlled by histone acyltransferases and histone deacetylases (HDACs), which influences cell proliferation and survival. Pan-HDAC and selective HDAC inhibitors have been employed in $\mathrm{PAH}$ and RV pressure overload models, yet with inconsistent results. Several studies have observed reduced PA remodeling, and with this reduced PA pressure, PVR and RVH in different PAH models $(84,85,87,89)$ (Table 2). One study could not detect any improvement of $\mathrm{PA}$ or $\mathrm{RV}$ remodeling in the $\mathrm{SuHx}$ rat model (88). In PAB-exposed rats, HDAC inhibition even had detrimental effects on RV function (86). These discrepancies might be related to the fact that HDAC activation is substantially different in the pulmonary circulation in different PAH models, and is further different between lung and RV (88). The potential anti-angiogenic and pro-apoptotic effects of HDAC inhibition, which may be beneficial in PA remodeling in PAH, could exert detrimental effects on the RV myocardium (88).

\section{Approaches specifically addressing $\mathrm{PA}$ remodeling in $\mathrm{PAH}$}

A number of therapeutic approaches that clearly target $\mathrm{PAH}$-specific mechanisms of PA remodeling are under investigation, and have been extensively reviewed elsewhere (110,113,143-146).

The pulmonary vasculature in PAH presents with a distinct phenotype of hyperproliferation, resistance to apoptosis and activation of specific signaling pathways (146). Current research focuses on a variety of molecules, with ambiguous results regarding the RV. For example, oncologic drugs have been evaluated for PAH therapy. Imatinib is a tyrosine kinase inhibitor that targets, amongst others, platelet-derived growth factor receptor (PDGFR) signaling, which importantly contributes to maladaptive PA remodeling in PAH. Imatinib impressively reversed pathological remodeling in experimental PAH (82). However, given that PDGF exerts positive effects on the myocardial level, e.g., mediates adaptive remodeling upon pressure overload $(147,148)$, the net benefit of imatinib on RHF in PAH remains elusive. Moreover, serious adverse events were observed in clinical studies, which resulted in termination of a recent trial (NCT01117987). Still, given promising results from investigations of $\mathrm{PAH}$ patients $(32,33)$, tyrosine kinase inhibition is under new clinical investigation in the UK ("Positioning Imatinib for Pulmonary Arterial Hypertension”; NIHR128465).

Modulation of the bone morphogenetic signaling in the pulmonary vasculature, and possibly also in the RV, is currently a "hot topic" in the field of $\mathrm{PH}(116,149)$ : Calvier et al. identified PPAR $\gamma$ as the missing link that regulates the complex balance between mitogenic, glucose metabolismpromoting transforming growth factor (TGF)- $\beta 1$ signals and vasoprotective BMP2/BMPR2 in vascular SMC (150). Several comprehensive studies aimed at either restoring BMPR2 expression and function using FK506 $(151,152)$, or rebalancing TGF- $\beta / \mathrm{BMP}$ signaling using the PPAR $\gamma$ agonist pioglitazone $(78,150,153)$ or ACTRIIA-Fc (sotatercept) which had therapeutic effects both at the preclinical (154) and clinical levels (NCT03738150). In addition, SMAD-specific E3 ubiquitin protein ligase 1 (SMURF1) has been identified as a critical regulator of BMP signaling, given that SMURF1 blood levels were increased in PAH patients and SMURF1-deficient mice were protected from PAH in the SuHx model (155). Early clinical studies of BMP-modulating therapies in patients with $\mathrm{PAH}$ provide positive proof of concept and the development of novel therapies in the area offers the promise of future patient benefit (sotatercept PULSAR phase 2 late breaking clinical study, American Thoracic Society 2020).

\section{Non-approved cell-based therapies}

Several key structural and molecular differences have 
been identified in both preclinical and clinical studies that distinguish between adaptive and maladaptive pathways for RV remodeling. Although the mechanisms underlying the shift from an adaptive to maladaptive phenotype are only beginning to be understood, it is clear that metabolic and neurohormonal dysfunction, capillary rarefaction, and profibrotic pathways are emerging as important elements (3). In particular, reduced microvascular density is thought to be a harbinger of maladaptive remodeling, and a leading cause of RHF in PAH patients $(143,156)$. RV biopsies from PAH patients with RHF show reduced microvascular density, as well as downregulation of angiogenic genes such as, VEGF and Ang-1 $(157,158)$. This suggests that the intrinsic link between microvascular rarefaction and pathological RV remodelling may drive the progression of $\mathrm{RV}$ failure in some patients that could be treated with angiogenic cell therapies. Indeed, stem cell therapies with pro-angiogenic properties targeted towards the RV may represent a novel therapeutic avenue to improve its function.

The RV may represent an excellent target for cellbased therapies given its tremendous plasticity and capacity to reverse remodeling when the afterload is removed. However, to date, most cell therapy studies have targeted the pulmonary circulation, though some of the benefits may be attributable to effects of the therapy on the RV. Mesenchymal stem cells (MSCs), endothelial progenitor cells (EPCs), and cardiac progenitor cells (CPCs) have all demonstrated efficacy in reducing RV systolic pressure (RVSP) and RV remodeling in animal models of PAH (159). Many of these studies also noted ancillary beneficial effects on RV function; however, it is not possible to discern whether cell therapy had a direct benefit on the RV or whether any improvements occurred merely as a result of afterload reduction. For this reason, a model system that is not affected by confounding influences from effects on the pulmonary vasculature, such as the PAB model, is needed in order to provide convincing evidence for a direct effect of cell therapy on the RV.

Moreover, these studies used intravenous, intrajugular, or intratracheal routes of administration that favours targeting of cells to the lung vasculature, and it is not known to what extent (if any) cells would be delivered to the RV. Indeed, studies of cell therapies targeted to the $\mathrm{LV}$ have revealed poor cell engraftment after intravenous delivery (160). However, this does not exclude the possibility of an indirect paracrine effect following the delivery of stem/ progenitor cells or cell-derived extracellular components [e.g., extracellular vesicles (EVs), miRNA]; for example, a reduction in inflammatory mediators, which could beneficially effect RV remodeling. Nonetheless, for a cellbased therapy to have maximal impact on RV function, local delivery of stem cells either by intramyocardial or intracoronary injection, would likely be preferable. Table 4 summarizes preclinical studies that have used models with a relatively fixed $\mathrm{RV}$ afterload (i.e., $\mathrm{PAB}$ or chronic thromboembolic models) to assess the effects of targeted RV delivery of CPCs, EPCs, mononuclear cells (MNCs), or MSCs on RV structure and function. It is encouraging that all these studies demonstrated improved RV function associated in many cases with increased RV capillary density, decreased RV fibrosis and RVH, as summarized in this table.

Although clinical trials targeting the LV have demonstrated that stem cell delivery via transcoronary, transatrial, intramyocardial and intravenous delivery is safe and feasible, they have produced mixed results regarding efficacy. There is more limited literature of targeted RV clinical cell therapy trials, and much of the available human evidence for RV targeted therapy comes from pediatric patients with CHD (10). The TICAP (Transcoronary Infusion of Cardiac Progenitor cells) phase 1 trial evaluated the safety of autologous cardiospherederived cells (CDC) in children with hypoplastic left heart syndrome (systemic RV) (165). In these patients, intracoronary CDC administration was safe and improved RVEF and clinical status as compared to patients that received standard therapy. The efficacy of CDC therapy for this patient population was recently confirmed in the phase 2 PERSEUS trial (Cardiac Progenitor Cell Infusion to Treat Univentricular Heart Disease) (166). Results demonstrate that CDCs markedly improve RV function (RVEF, 3 months $\uparrow 6.4 \%, 12$ months $\uparrow 7.4 \%$ ) and heart failure status and mitigate cardiac fibrosis. Moreover, in a preclinical $\mathrm{PAB}$ model, intramyocardial administration of CPCs improved RV contractile function, increased RV microvascular density, and reduced RVH and fibrosis (161). The study further demonstrated that the proangiogenic and antifibrotic actions of CPCs were mediated by exosomes $\left(\mathrm{CD}^{+}, 96.1 \pm 6.1 \mathrm{~nm}\right)$. A phase 1 study (ALPHA trial: NCT03145298) is currently evaluating the safety and feasibility of intravenous delivery of allogeneic human CDC in patients with PAH. In this trial, an exploratory endpoint is evaluating the effect of cell therapy on RV function and pulmonary hemodynamics. Two other trials are currently ongoing assessing the safety and efficacy of adiposederived MSC (NCT04055415), and eNOS-enhanced 
Table 4 Preclinical studies evaluating the efficacy of RV targeted cell therapy

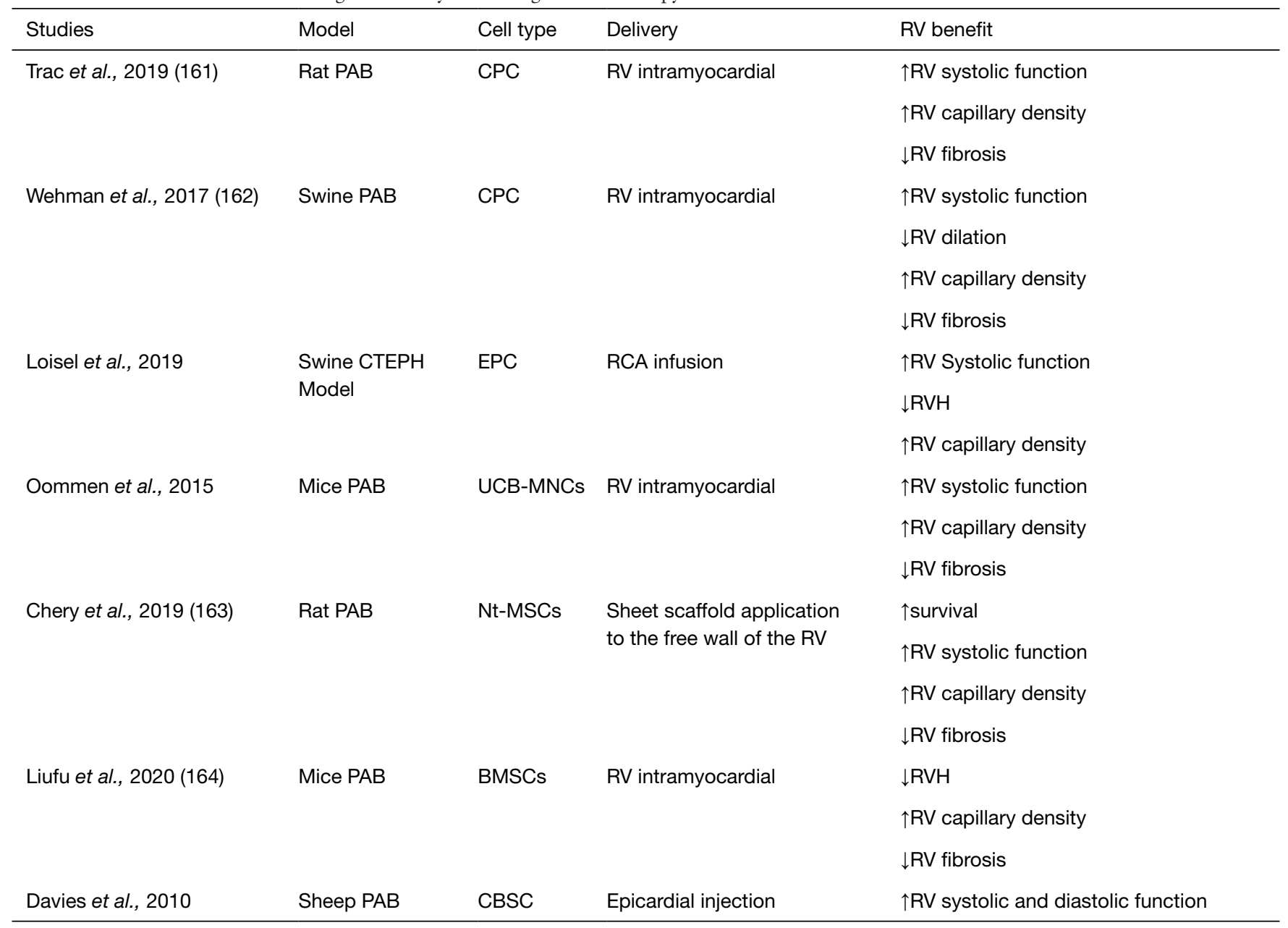

CBSC, cord blood stem cell; PAB, pulmonary artery banding; CTEPH, chronic thromboembolic pulmonary hypertension; BMSCs, bone marrow derived MSC; UCB, umbilical cord blood; Nt-MSCs, neonatal thymus MSC.

EPCs (SAPPHIRE, NCT03001414) in patients with PAH. While these studies are targeting the lung vasculature by delivering cells intravenously, RV structure and function will be assessed as a secondary endpoint.

Several recent studies have explored the intravenous effect of MSC-derived EVs, on PA remodeling, RVH and pressure, in rodent models of $\mathrm{PAH}$, such as SuHx rat $(167,168)$ and MCT rat $(169)$. Others have investigated the effect of intravenous delivery of EVs for treatment of $\mathrm{PH}$ associated with bronchopulmonary dysplasia (170), and a clinical trial is underway (NCT03857841). However, as mentioned above no direct effect on the hypertensive RV can be demonstrated in these studies due to the animal models used.

To our knowledge, no human trial is currently assessing the impact of intramyocardial or intracoronary administration of stem cells or stem-cell derived components (e.g., EVs) in patients with $\mathrm{PAH}$ and RV failure. This relatively unexplored therapeutic avenue may have tremendous potential as RV function is a critical determinant of prognosis, with RV failure representing the leading cause of death in these patients (1). The accumulating preclinical evidence seems to suggest a direct and robust $\mathrm{RV}$ benefit, providing a strong rationale for future translation to human trials.

\section{Non-approved RNA-based therapies}

Noncoding RNAs, including microRNA (miRNA), long non-coding RNA (lncRNA), circular RNA (circRNA), and 
Y RNAs in CVD have been comprehensively reviewed elsewhere (171-173). Although non-coding RNA-based therapy in LHF has received significant attention in both preclinical models and, to a lesser degree, in clinical trials (NCT04045405; NCT03603431) (173), its therapeutic potential in RV failure remains largely unexplored.

At the molecular level RV remodeling is characterized by a return to a fetal-like pattern of energy substrate metabolism, enhanced inflammation and ischemia due to capillary rarefaction (174) promoting the loss of cardiomyocytes and the appearance of pronounced interstitial and perivascular collagen deposition (fibrosis) (175). With the technological advances of "omics", numerous studies have linked these changes to the altered expression of many non-coding RNAs including lncRNAs, miRNAs and circRNAs (176-178), but so far only few miRNAs have been therapeutically investigated directly in the RV.

\section{miRNA-based therapies for PAH-associated RV dysfunction}

Although in vivo modulation of miRNA expression levels is challenging (179), the development of synthetic small duplex RNA designed to specifically inhibit (AntimiR) or supplement (mimics) endogenous miRNAs now represents a promising approach to treat various disorders. This approach has been extensively explored in animal models of $\mathrm{PH}$ to prevent or reverse pulmonary vascular remodeling (180-183), and most of the studies showed improvement in $\mathrm{PH}$ and in $\mathrm{RV}$ function. However, to the best of our knowledge, only the role of miR-126 (158), miR-208 (184), and miR-223 (185) have been investigated in RV failure independently of the effects on the lungs. miR-126 is known as an angiogenesis-regulating miRNA. It is one of the few EC-specific miRNAs, and regulates vascular integrity and developmental angiogenesis. miR-126 was downregulated in both the failing human and rat RV and negatively correlated with disease severity. Its enforced expression in vivo using mimics improved RV function by increasing vascular density and reducing fibrosis (158). Along with miR-126, the muscle-specific miRNA miR-208a was also decreased during RV decompensation. Its diminution associated with the rise in TNF-mediated inflammatory response was suggested to indirectly repress the transcription factor MEF-2, thus promoting entrance into a decompensated phase (184). Finally, miR-223 is known to be downregulated in many hyperproliferative diseases like cancer and $\mathrm{PH}$, but has also profound effects on RV function independent of its function in the lung. miR-223 overexpression targeting cardiomyocytes improved $\mathrm{CO}$ in animals exposed to HOX, whereas its downregulation in rats subjected to PAB elicited opposite effects (185). Despite the fact that $\mathrm{RV}$-based research remains the Cinderella area of most $\mathrm{PH}$ research, several new treatments exhibiting important $\mathrm{RV}$ improvement in $\mathrm{PH}$ models have been preclinically identified and are now under clinical investigation (144). Although for most of the new (experimental and approved) therapies effects on non-coding RNA signaling remains unknown, some of these treatments have clearly shown their ability to regulate non-coding RNA expression. For example, PPAR $\gamma$ activation by pioglitazone fully reversed $\mathrm{PH}$ and prevented $\mathrm{RV}$ failure, as mentioned above. The restoration of disturbed lipid metabolism and mitochondrial morphology/function led to normalization of the expression of several miRNAs (78). Consistently, pre-miRs-197 and -146b greatly repressed genes that drive FAO (Cpt1b, Fabp4) in cultured primary cardiomyocytes. Importantly, these major pathogenic findings in SuHx rats were recapitulated in human end-stage PAH, i.e., miR-197 and miR-146b were upregulated in the pressure-overloaded failing RV (78). A clinical trial was launched on the use for pioglitazone in PAH (NCT00825266) but was terminated due to difficulties in recruitment, probably because of insulin resistance being a mandatory inclusion criterion.

In human PASMC, the BMP2/BMPR2-PPAR $\gamma$ axis upregulated miR-148a and miR-331-5p, thereby inhibiting SMC proliferation and glucose metabolism $(150,153)$. miR-331-5p downregulated the platelet isoform of phosphofructokinase (PFKP) messenger RNA (150), a rate limiting enzyme of glycolysis and, as such, a proproliferative factor that is overexpressed in situ in the pulmonary arteries of patients with idiopathic PAH. However, neither the aforementioned axis nor downstream miRNA have been studied systematically in the hypertensive $\mathrm{RV}$ or cultured cardiomyocytes.

\section{LncRNA-based therapies for RHF}

It has been demonstrated recently, that the lncRNA H19 is causally involved in pathological RV remodeling and has a predictive value (186). Silencing H19 reduced RV remodeling and improved RV function in MCT and $\mathrm{PAB}$ rat models. In PAH patients it was upregulated particularly in decompensated RV, and circulating $\mathrm{H} 19$ levels predicted survival in PAH patients (186). Whereas these findings identify $\mathrm{H} 19$ as a promising therapeutic target, they at 
the same time underscore the fundamental differences between the LV and RV, given that $\mathrm{H} 19$ has been shown to be downregulated in failing LV and that gene therapy augmenting cardiac H19 levels reversed pressure-induced LHF (187).

\section{PA denervation}

Patients with PAH show signs of sympathetic overdrive (188) that is associated with adverse clinical outcomes (189). Lungs and pulmonary vasculature contribute to circulating catecholamine levels (190) and are one of the major sites of ACE expression and AngII production. Modulation of the sympathetic and renin-angiotensin-aldosterone systems is an established treatment for heart failure. Both $\beta$-blockers and ACE inhibitors have been shown to attenuate disease in experimental models $(40,42,191)$, however, there is no evidence of benefit in patients with PAH $(20,192,193)$. Targeted, catheter-based, renal denervation reduces blood pressure in patients with systemic hypertension both on or off anti-hypertensive therapy (194-196). The development of such technologies offers the opportunity to modulate sympathetic activity through targeted denervation of the pulmonary vasculature, potentially avoiding the adverse effects of systemically active therapies.

Sympathetic and parasympathetic nerves derived from the spinal ganglions (sympathetic) and vagus nerve (parasympathetic) merge to form the pulmonary plexus, which was larger around the main PA (197). Running with the pulmonary vasculature, nerves branch, reducing in size after the bifurcation of the main PA forming a circumferential network around the vessels before the hilum of the lungs. Preclinical studies have demonstrated that pulmonary artery denervation (PDN) improves pulmonary haemodynamics in acute $(198,199)$ and chronic models of PH (200). The application of radiofrequency energy, which induces long-term alterations in nerve conduction, to a specific location at the bifurcation is reported to provide an acute improvement in hemodynamic status that persists to 3 months despite the withdrawal of disease-specific therapy in patients with PAH (201). Early indicators of efficacy have also been reported in patients with chronic thromboembolic pulmonary hypertension (CTEPH) and left heart disease associated PH $(202,203)$.

Current European guidelines indicate that patients with PAH and high-risk features should be treated with two disease-specific therapies (204). Using an alternative catheter-based ultrasound denervation procedure (197) the recent TROPHY study enrolled 23 patients with PAH established on a minimum of dual oral therapy (205). Four to 6 months following ultrasound PDN, PVR was reduced by $94 \mathrm{dyn} \cdot \mathrm{s} \cdot \mathrm{cm}^{-5}$ and 6 -minute walking distance $(6 \mathrm{MWD})$ increased by $42 \mathrm{~m}$, a result that is congruent with a minimally important clinical difference of $33 \mathrm{~m}$ (206). The observed increase in daily activity and improved clinical risk score further indicate a potential benefit of this novel therapy, on a background of guideline-directed medical therapy.

Further studies are required to evaluate efficacy, safety, and clinical impact of PDN in patients with $\mathrm{PAH}$ and other forms of pulmonary hypertension.

\section{Mechanical circulatory support (MCS)}

In contrast to MCS for LHF, MCS for RHF is still in its early stages and experience is, with a few exceptions, limited to case reports and series. Indications comprise acute myocardial infarction, pulmonary embolism, postcardiac surgery, post heart transplantation, myocarditis as well as decompensated chronic heart failure and thus mostly involve concomitant left ventricular disease. A special indication is RHF after LVAD implantation. It is important to differentiate between acute MCS and efforts to achieve durable results. In general, RHF may be bridged by bypassing the $\mathrm{RV}$ [right atrium (RA) to $\mathrm{PA}$ ] or the $\mathrm{RV}$ and LV [RA to aorta (AO)], and there is considerable debate which approach should be used in different conditions. Most centers prefer a bypass of both ventricles in conditions where pulmonary resistance is elevated by the condition, such as pulmonary hypertension or pulmonary embolism. In contrast, a pure RV bypass is usually employed when RV failure results from a cardiac cause, such as RV myocardial infarction.

\section{Acute MCS}

The percutaneous Impella RP microaxial pump is introduced via the femoral vein and transports blood from the RA to the PA via an impeller. It has no option to oxygenate blood. The Tandem Heart right ventricular assist device (RVAD) requires two femoral vein cannulations, one for the draining cannula placed in the RA and one for the outflow cannula placed in the PA. Cannulation of right jugular vein is used in some cases. Additional oxygenation and carbon dioxide removal is possible with 
Table 5 Overview of mechanical circulatory support

\begin{tabular}{|c|c|c|c|c|}
\hline Device & Draining & Outflow & $\begin{array}{l}\text { Approved time } \\
\text { of use }\end{array}$ & Studies \\
\hline \multicolumn{5}{|l|}{ Acute MCS } \\
\hline Tandem Heart & RA & $\mathrm{PA}$ & $4 d$ & $\begin{array}{l}\mathrm{n}=46 \text { (18 post-cardiac surgery, } 12 \text { myocardial infarction, } 5 \text { LVAD, } 5 \text { post } \\
\text { HTX), in-hospital mortality } 57 \%(209)\end{array}$ \\
\hline V-Pa ECMO & RA & $\mathrm{PA}$ & $30 d$ & Restricted to case series \\
\hline V-A ECMO & RA & FA & $30 \mathrm{~d}$ & $\begin{array}{l}\mathrm{n}=179 \text { (70 post-cardiac surgery, } 46 \text { myocardial infarction), in-hospital mor- } \\
\text { tality } 39 \%(210)\end{array}$ \\
\hline CentriMag & RA & PA & $30 \mathrm{~d}$ & $\begin{array}{l}\mathrm{n}=38 \text { ( } 14 \text { myocardial infarction, } 12 \text { LVAD, } 12 \text { post-cardiac surgery), mean } \\
\text { duration of support } 13 \mathrm{~d}(1-60 \mathrm{~d}) \text {, in-hospital mortality } 58 \%, 30 \mathrm{~d}(211)\end{array}$ \\
\hline \multirow[t]{2}{*}{$\begin{array}{l}\text { Heart Ware/ } \\
\text { Heart Mate } 3\end{array}$} & $\mathrm{RV}$ & PA & - & $\begin{array}{l}\text { Heart Ware (meta-analysis): } n=56 \text { ( } 85 \% \text { non-ischemic cardiomyopathy), } \\
30 \text {-day mortality } 9 \% \text {, time on device } 156 \text { (IQR, 66-351), heart } \\
\text { transplantation } 46 \%(212)\end{array}$ \\
\hline & & & & $\begin{array}{l}\text { Heart Mate } 3: \mathrm{n}=14 \text { ( } 50 \% \text { DCM; } 28 \% \text { ICM), } 9 \text { patients died within } 6 \\
\text { months, } 1 \text { successful heart transplantation, } 8 \text { patients continuing support } \\
\text { for } 266 \text { (95-636 days) (213) }\end{array}$ \\
\hline $\begin{array}{l}\text { Total artificial } \\
\text { heart* }^{\star}\end{array}$ & RA & $\begin{array}{l}\text { PA (requires RV } \\
\text { explantation) }\end{array}$ & - & $\begin{array}{l}n=450 \text { (50\% DCM, 20\% ICM), } 266 \text { underwent heart transplantation, } \\
12 \text {-month survival 53\% (214) }\end{array}$ \\
\hline BiVACOR $^{*}$ & \multicolumn{2}{|c|}{ Requires native cardiectomy } & - & Pre-clinical \\
\hline
\end{tabular}

*, biventricular support devices. DCM, dilated cardiomyopathy; ECMO, extracorporeal membrane oxygenation; FA, femoral artery; ICM, ischemic cardiomyopathy; LVAD, left ventricular assist device; PA, pulmonary artery; RA, right atrium; RV, right ventricle; V-A, veno-arterial; $\mathrm{V}-\mathrm{Pa}$, veno-pulmonary arterial.

this system. The same configuration can be built with standard extracorporeal membrane oxygenation (ECMO) machines, using a femoral venous draining cannula and a flexible supply cannula, which is inserted through the jugular vein and the RV to the PA (207). The Protek Duo dual-lumen cannula, which is also commonly inserted via the jugular vein, combines right artery draining and PA outflow in one cannula. Veno-arterial ECMO (V-A ECMO) differs from the previous systems in that it delivers blood from the RA via an oxygenator to the arterial circulation. As a consequence, these systems increase left ventricular afterload, thereby promoting pulmonary edema particularly in the presence of left ventricular dysfunction. The most important characteristics of the described systems are summarized in Table 5.

\section{Durable MCS}

Durable MCS devices were formerly implanted as bridgeto-transplantation. Recently, durable MCS is more frequently employed as destination therapy, given the shortage of donor hearts. In addition, it is used as bridgeto-decision, i.e., in instances where support is required for prolonged time intervals. All systems require surgical implantation and can be divided into those employing extracorporeal pumps (Berlin Heart Excor, Total artificial heart) and fully implantable systems. For the former, inhospital treatment is mandatory because of their set-up and the intense supervision required. The latter mostly comprise LVAD connected to the RA (draining) and PA (outflow), with implantation techniques increasingly being 
adapted and smaller systems emerging which might be better suitable for RV support. Evidence for all of these systems is restricted to case examples.

\section{Conclusion and perspective}

Despite remarkable advancements in PAH therapy during the last decade, PAH-related mortality, especially from RV failure, remains high. It is a matter of debate whether PAH patients will substantially benefit from therapies directly targeting the RV myocardium. Particularly promising, novel therapeutic targets in RHF include RV metabolic imbalance, inflammation and oxidative stress.

Besides pharmacological therapies (be it "repurposed" or newly developed), cell and RNA-based therapies have generated substantial recognition, due to solid preclinical and early clinical study results. Discrepant mechanistic profiles in different pre-clinical models and contrasting pathomechanisms in the pulmonary vasculature and $\mathrm{RV}$ myocardium in PAH complicate the development of effective therapeutics. Further experimental research and clinical studies are required to successfully advance therapeutic options for $\mathrm{PAH}$ and RV failure.

\section{Acknowledgments}

Funding: VR is supported by the German Research Foundation (DFG, RU1678/3-3). GH receives financial support from the DFG (HA4348/2-2 and HA4348/6-2 KFO311), the Federal Ministry of Education and Research (BMBF ViP+ program-03VP08053; BMBF 01KC2001B) and the European Pediatric Pulmonary Vascular Disease Network (www.pvdnetwork.org). AMKR is supported by a Wellcome Trust Clinical Research Career Development Fellowship (206632/Z/17/Z).

\section{Footnote}

Provenance and Peer Review: This article was commissioned by the editorial office, Cardiovascular Diagnosis and Therapy for the series "Right Ventricular Dysfunction". The article was sent for external peer review organized by the Editorin-Chief and the editorial office.

Peer Review File: Available at http://dx.doi.org/10.21037/ cdt-20-592

Conflicts of Interest: All authors have completed the ICMJE uniform disclosure form (available at http://dx.doi. org/10.21037/cdt-20-592). The series "Right Ventricular Dysfunction" was commissioned by the editorial office without any funding or sponsorship. GH served as the unpaid Guest Editor of the series. LCN reports grants and personal fees from Abiomed, grants and personal fees from Cytosorbents, personal fees from Maquet, personal fees from Orion, personal fees from Abbott, personal fees from Zoll, personal fees from Bayer, non-financial support from Edwards, all outside the submitted work. AMKR reports grants from Medical Research Council (UK) and Wellcome Trust (206632/Z/17/Z), research support from Actelion, Novartis, Medtronic, Abbott, and personal fees and research support from SoniVie and Endotronix. SB reports personal fees from Actelion, personal fees from Janssen, personal fees from Allienaire, personal fees from morphic therapeutic, outside the submitted work. The other authors have no other conflicts of interest to declare.

Ethical Statement: The authors are accountable for all aspects of the work in ensuring that questions related to the accuracy or integrity of any part of the work are appropriately investigated and resolved.

Open Access Statement: This is an Open Access article distributed in accordance with the Creative Commons Attribution-NonCommercial-NoDerivs 4.0 International License (CC BY-NC-ND 4.0), which permits the noncommercial replication and distribution of the article with the strict proviso that no changes or edits are made and the original work is properly cited (including links to both the formal publication through the relevant DOI and the license). See: https://creativecommons.org/licenses/by-nc-nd/4.0/.

\section{References}

1. Sanders JL, Koestenberger M, Rosenkranz S, et al. Right ventricular dysfunction and long-term risk of death. Cardiovasc Diagn Ther 2020;10:1646-58.

2. Konstam MA, Kiernan MS, Bernstein D, et al. Evaluation and Management of Right-Sided Heart Failure: A Scientific Statement From the American Heart Association. Circulation 2018;137:e578-e622.

3. Agrawal V, Lahm T, Hansmann G, et al. Molecular mechanisms of right ventricular dysfunction in pulmonary arterial hypertension: focus on the coronary vasculature, sex hormones, and glucose/lipid metabolism. Cardiovasc Diagn Ther 2020;10:1522-40. 
4. Inampudi C, Tedford RJ, Hemnes AR, et al. Treatment of right ventricular dysfunction and heart failure in pulmonary arterial hypertension. Cardiovasc Diagn Ther 2020;10:1659-74.

5. Heinzel FR, Hegemann N, Hohendanner F, et al. Left ventricular dysfunction in heart failure with preserved ejection fraction-molecular mechanisms and impact on right ventricular function. Cardiovasc Diagn Ther 2020;10:1541-60.

6. Haddad F, Hunt SA, Rosenthal DN, et al. Right ventricular function in cardiovascular disease, part I: Anatomy, physiology, aging, and functional assessment of the right ventricle. Circulation 2008;117:1436-48.

7. Bogaard HJ, Abe K, Vonk Noordegraaf A, et al. The right ventricle under pressure: cellular and molecular mechanisms of right-heart failure in pulmonary hypertension. Chest 2009; 135:794-804.

8. Reddy S, Bernstein D. Molecular mechanisms of right ventricular failure. Circulation 2015;132:1734-42.

9. Bernardo RJ, Haddad F, Couture EJ, et al. Mechanics of right ventricular dysfunction in pulmonary arterial hypertension and heart failure with preserved ejection fraction. Cardiovasc Diagn Ther 2020;10:1580-603.

10. Santens B, Van De Bruaene A, De Meester P, et al. Diagnosis and treatment of right ventricular dysfunction in congenital heart disease. Cardiovasc Diagn Ther 2020;10:1625-45.

11. Handoko ML, De Man FS, Allaart CP, et al. Perspectives on novel therapeutic strategies for right heart failure in pulmonary arterial hypertension: Lessons from the left heart. Eur Respir Rev 2010;19:72-82.

12. Tello K, Dalmer A, Vanderpool R, et al. Impaired right ventricular lusitropy is associated with ventilatory inefficiency in pulmonary arterial hypertension. Eur Respir J 2019;54:1900342.

13. Redfield MM, Chen HH, Borlaug BA, et al. Effect of phosphodiesterase-5 inhibition on exercise capacity and clinical status in heart failure with preserved ejection fraction: a randomized clinical trial. JAMA 2013;309:1268-77.

14. Hoendermis ES, Liu LCY, Hummel YM, et al. Effects of sildenafil on invasive haemodynamics and exercise capacity in heart failure patients with preserved ejection fraction and pulmonary hypertension: A randomized controlled trial. Eur Heart J 2015;36:2565-73.

15. Koller B, Steringer-Mascherbauer R, Ebner CH, et al. Pilot Study of Endothelin Receptor Blockade in Heart Failure with Diastolic Dysfunction and Pulmonary Hypertension (BADDHY-Trial). Heart Lung Circ
2017;26:433-41.

16. Vachiéry JL, Delcroix M, Al-Hiti H, et al. Macitentan in pulmonary hypertension due to left ventricular dysfunction. Eur Respir J 2018;51:1701886.

17. Gulati G, Grandin EW, Kennedy K, et al. Preimplant phosphodiesterase-5 inhibitor use is associated with higher rates of severe early right heart failure after left ventricular assist device implantation an INTERMACS analysis. Circ Heart Fail 2019;12:e005537.

18. Farha S, Saygin D, Park MM, et al. Pulmonary arterial hypertension treatment with carvedilol for heart failure: a randomized controlled trial. JCI Insight 2017;2:e95240.

19. Giardini A, Lovato L, Donti A, et al. A pilot study on the effects of carvedilol on right ventricular remodelling and exercise tolerance in patients with systemic right ventricle. Int J Cardiol 2007;114:241-6.

20. van Campen JS, de Boer K, van de Veerdonk MC, et al. Bisoprolol in idiopathic pulmonary arterial hypertension: an explorative study. Eur Respir J 2016;48:787-96.

21. Rijnierse MT, Groeneveldt JA, van Campen JSJA, et al. Bisoprolol therapy does not reduce right ventricular sympathetic activity in pulmonary arterial hypertension patients. Pulm Circ 2020;10:2045894019873548.

22. Maron BA, Waxman AB, Opotowsky AR, et al. Effectiveness of spironolactone plus ambrisentan for treatment of pulmonary arterial hypertension (from the [ARIES] Study 1 and 2 Trials). Am J Cardiol 2013;112:720-5.

23. Rich S, Martinez J, Lam W, et al. Captopril as treatment for patients with pulmonary hypertension. Problem of variability in assessing chronic drug treatment. Br Heart J 1982;48:272-7.

24. Leier CV, Bambach D, Nelson S, et al. Captopril in primary pulmonary hypertension. Circulation 1983;67:155-61.

25. Michelakis ED, Gurtu V, Webster L, et al. Inhibition of pyruvate dehydrogenase kinase improves pulmonary arterial hypertension in genetically susceptible patients. Sci Transl Med 2017;9:eaao4583.

26. Khan SS, Cuttica MJ, Beussink-Nelson L, et al. Effects of ranolazine on exercise capacity, right ventricular indices, and hemodynamic characteristics in pulmonary arterial hypertension: A pilot study. Pulm Circ 2015;5:547-56.

27. Gomberg-Maitland M, Schilz R, Mediratta A, et al. Phase I safety study of ranolazine in pulmonary arterial hypertension. Pulm Circ 2015;5:691-700.

28. Hernández-Sánchez J, Harlow L, Church C, et al. Clinical trial protocol for TRANSFORM-UK: A therapeutic open-label study of tocilizumab in the 
treatment of pulmonary arterial hypertension. Pulm Circ 2018;8:2045893217735820.

29. Trankle CR, Canada JM, Kadariya D, et al. IL-1 blockade reduces inflammation in pulmonary arterial hypertension and right ventricular failure: A single-arm, open-label, phase Ib/II pilot study. Am J Respir Crit Care Med 2019;199:381-4.

30. Boucherat O, Provencher S. Therapeutic value of ASK1 inhibition in pulmonary arterial hypertension. Am J Respir Crit Care Med 2018;197:284-6.

31. Hemnes AR, Rathinasabapathy A, Austin EA, et al. A potential therapeutic role for angiotensin-converting enzyme 2 in human pulmonary arterial hypertension. Eur Respir J 2018;51:1702638.

32. Ghofrani HA, Morrell NW, Hoeper MM, et al. Imatinib in pulmonary arterial hypertension patients with inadequate response to established therapy. Am J Respir Crit Care Med 2010;182:1171-7.

33. Ghofrani HA, Seeger W, Grimminger F. Imatinib for the treatment of pulmonary arterial hypertension. N Engl J Med 2005;353:1412-3.

34. Borgdorff MA, Bartelds B, Dickinson MG, et al. Sildenafil treatment in established right ventricular dysfunction improves diastolic function and attenuates interstitial fibrosis independent from afterload. Am J Physiol Heart Circ Physiol 2014;307:H361-9.

35. Gomez-Arroyo J, Sakagami M, Syed AA, et al. Iloprost reverses established fibrosis in experimental right ventricular failure. Eur Respir J 2015;45:449-62.

36. Rai N, Veeroju S, Schymura Y, et al. Effect of Riociguat and Sildenafil on Right Heart Remodeling and Function in Pressure Overload Induced Model of Pulmonary Arterial Banding. Biomed Res Int 2018;2018: 3293584.

37. Andersen A, van der Feen DE, Andersen S, et al. Animal models of right heart failure. Cardiovasc Diagn Ther 2020;10:1561-79.

38. Borgdorff MAJ, Bartelds B, Dickinson MG, et al. Sildenafil enhances systolic adaptation, but does not prevent diastolic dysfunction, in the pressure-loaded right ventricle. Eur J Heart Fail 2012;14:1067-74.

39. Ishikawa M, Sato N, Asai K, et al. Effects of a pure $\alpha /$ $\beta$-adrenergic receptor blocker on monocrotaline-induced pulmonary arterial hypertension with right ventricular hypertrophy in rats. Circ J 2009;73:2337-41.

40. de Man FS, Handoko ML, Van Ballegoij JJM, et al. Bisoprolol delays progression towards right heart failure in experimental pulmonary hypertension. Circ Heart Fail 2012;5:97-105.
41. Bogaard HJ, Natarajan R, Mizuno S, et al. Adrenergic receptor blockade reverses right heart remodeling and dysfunction in pulmonary hypertensive rats. Am J Respir Crit Care Med 2010;182:652-60.

42. Perros F, Ranchoux B, Izikki M, et al. Nebivolol for improving endothelial dysfunction, pulmonary vascular remodeling, and right heart function in pulmonary hypertension. J Am Coll Cardiol 2015;65:668-80.

43. Piao L, Fang YH, Parikh KS, et al. GRK2-mediated inhibition of adrenergic and dopaminergic signaling in right ventricular hypertrophy: Therapeutic implications in pulmonary hypertension. Circulation 2012;126:2859-69.

44. Cowley PM, Wang G, Joshi S, et al. $\alpha 1$ A-Subtype adrenergic agonist therapy for the failing right ventricle. Am J Physiol Heart Circ Physiol 2017;313:H1109-18.

45. Cowley PM, Wang G, Swigart PM, et al. Reversal of right ventricular failure by chronic $\alpha 1 \mathrm{~A}$-subtype adrenergic agonist therapy. Am J Physiol Heart Circ Physiol 2019;316:H224-32.

46. de Man FS, Tu L, Handoko ML, et al. Dysregulated renin-angiotensin-aldosterone system contributes to pulmonary arterial hypertension. Am J Respir Crit Care Med 2012;186:780-9.

47. Rouleau JL, Kapuku G, Pelletier S, et al. Cardioprotective effects of ramipril and losartan in right ventricular pressure overload in the rabbit: importance of kinins and influence on angiotensin II type 1 receptor signaling pathway. Circulation 2001;104:939-44.

48. Sharifi Kia D, Benza E, Bachman TN, et al. Angiotensin Receptor-Neprilysin Inhibition Attenuates Right Ventricular Remodeling in Pulmonary Hypertension. J Am Heart Assoc 2020;9:e015708.

49. Borgdorff MA, Bartelds B, Dickinson MG, et al. A cornerstone of heart failure treatment is not effective in experimental right ventricular failure. Int J Cardiol 2013;169:183-9.

50. Johnson JA, West J, Maynard KB, et al. ACE2 improves right ventricular function in a pressure overload model. PLoS One 2011;6:e20828.

51. Shenoy V, Kwon KC, Rathinasabapathy A, et al. Oral delivery of angiotensin-converting enzyme 2 and angiotensin-(1-7) bioencapsulated in plant cells attenuates pulmonary hypertension. Hypertension 2014;64:1248-59.

52. Shenoy V, Gjymishka A, Jarajapu YP, et al. Diminazene attenuates pulmonary hypertension and improves angiogenic progenitor cell functions in experimental models. Am J Respir Crit Care Med 2013;187:648-57.

53. Preston IR, Sagliani KD, Warburton RR, et al. 
Mineralocorticoid receptor antagonism attenuates experimental pulmonary hypertension. Am J Physiol Lung Cell Mol Physiol 2013;304:L678-88.

54. Maron BA, Zhang YY, White K, et al. Aldosterone inactivates the endothelin-B receptor via a cysteinyl thiol redox switch to decrease pulmonary endothelial nitric oxide levels and modulate pulmonary arterial hypertension. Circulation 2012;126:963-74.

55. Maron BA, Oldham WM, Chan SY, et al. Upregulation of steroidogenic acute regulatory protein by hypoxia stimulates aldosterone synthesis in pulmonary artery endothelial cells to promote pulmonary vascular fibrosis. Circulation 2014;130:168-79.

56. Boehm M, Arnold N, Braithwaite A, et al. Eplerenone attenuates pathological pulmonary vascular rather than right ventricular remodeling in pulmonary arterial hypertension. BMC Pulm Med 2018;18:41.

57. Grzegorzewska AP, Seta F, Han R, et al. Dimethyl Fumarate ameliorates pulmonary arterial hypertension and lung fibrosis by targeting multiple pathways. Sci Rep 2017;7:41605.

58. Eba S, Hoshikawa Y, Moriguchi T, et al. The nuclear factor erythroid 2-related factor 2 activator oltipraz attenuates chronic hypoxia-induced cardiopulmonary alterations in mice. Am J Respir Cell Mol Biol 2013;49:324-33.

59. Redout EM, Van Der Toorn A, Zuidwijk MJ, et al. Antioxidant treatment attenuates pulmonary arterial hypertension-induced heart failure. Am J Physiol Heart Circ Physiol 2010;298:H1038-47.

60. Nisbet RE, Bland JM, Kleinhenz DJ, et al. Rosiglitazone attenuates chronic hypoxia-induced pulmonary hypertension in a mouse model. Am J Respir Cell Mol Biol 2010;42:482-90.

61. Klinke A, Möller A, Pekarova M, et al. Protective effects of 10-nitro-oleic acid in a hypoxia-induced murine model of pulmonary hypertension. Am J Respir Cell Mol Biol 2014;51:155-62.

62. Klinke A, Berghausen E, Friedrichs K, et al. Myeloperoxidase aggravates pulmonary arterial hypertension by activation of vascular Rho-kinase. JCI Insight 2018;3:e97530.

63. Yoshida K, Abe K, Ishikawa M, et al. Inhibition of TLR9$\mathrm{NF}-\kappa \mathrm{B}-$ mediated sterile inflammation improves pressure overload-induced right ventricular dysfunction in rats. Cardiovasc Res 2019;115:658-68.

64. Budas GR, Boehm M, Kojonazarov B, et al. ASK1 inhibition halts disease progression in preclinical models of pulmonary arterial hypertension. Am J Respir Crit Care
Med 2018;197:373-85.

65. Kojonazarov B, Novoyatleva T, Boehm M, et al. P38 mapk inhibition improves heart function in pressure-loaded right ventricular hypertrophy. Am J Respir Cell Mol Biol 2017;57:603-14.

66. Zhang LL, Lu J, Li MT, et al. Preventive and remedial application of etanercept attenuate monocrotalineinduced pulmonary arterial hypertension. Int $\mathrm{J}$ Rheum Dis 2016;19:192-8.

67. Mutschler D, Wikström G, Lind L, et al. Etanercept reduces late endotoxin-induced pulmonary hypertension in the pig. J Interferon Cytokine Res 2006;26:661-7.

68. Tamura Y, Phan C, Tu L, et al. Ectopic upregulation of membrane-bound IL6R drives vascular remodeling in pulmonary arterial hypertension. J Clin Invest 2018;128:1956-70.

69. Voelkel NF, Tuder RM, Bridges J, et al. Interleukin-1 receptor antagonist treatment reduces pulmonary hypertension generated in rats by monocrotaline. Am J Respir Cell Mol Biol 1994;11:664-75.

70. Piao L, Fang YH, Cadete VJJ, et al. The inhibition of pyruvate dehydrogenase kinase improves impaired cardiac function and electrical remodeling in two models of right ventricular hypertrophy: Resuscitating the hibernating right ventricle. J Mol Med 2010;88:47-60.

71. Michelakis ED, McMurtry MS, Wu XC, et al. Dichloroacetate, a metabolic modulator, prevents and reverses chronic hypoxic pulmonary hypertension in rats: Role of increased expression and activity of voltage-gated potassium channels. Circulation 2002;105:244-50.

72. McMurtry MS, Bonnet S, Wu X, et al. Dichloroacetate prevents and reverses pulmonary hypertension by inducing pulmonary artery smooth muscle cell apoptosis. Circ Res 2004;95:830-40.

73. Bøgh N, Hansen ESS, Omann C, et al. Increasing carbohydrate oxidation improves contractile reserves and prevents hypertrophy in porcine right heart failure. Sci Rep 2020;10:8158.

74. Fang YH, Piao L, Hong Z, et al. Therapeutic inhibition of fatty acid oxidation in right ventricular hypertrophy: Exploiting Randle's cycle. J Mol Med 2012;90:31-43.

75. Liu F, Yin L, Zhang L, et al. Trimetazidine improves right ventricular function by increasing miR-21 expression. Int J Mol Med 2012;30:849-55.

76. Hemnes AR, Brittain EL, Trammell AW, et al. Evidence for right ventricular lipotoxicity in heritable pulmonary arterial hypertension. Am J Respir Crit Care Med 2014;189:325-34. 
77. Brittain EL, Talati M, Fortune N, et al. Adverse physiologic effects of Western diet on right ventricular structure and function: role of lipid accumulation and metabolic therapy. Pulm Circ 2019;9:2045894018817741.

78. Legchenko E, Chouvarine P, Borchert P, et al. PPAR $\gamma$ agonist pioglitazone reverses pulmonary hypertension and prevents right heart failure via fatty acid oxidation. Sci Transl Med 2018;10:eaao0303.

79. Hansmann G, Wagner RA, Schellong S, et al. Pulmonary arterial hypertension is linked to insulin resistance and reversed by peroxisome proliferator-activated receptor- $\gamma$ activation. Circulation 2007;115:1275-84.

80. Kim EK, Lee JH, Oh YM, et al. Rosiglitazone attenuates hypoxia-induced pulmonary arterial hypertension in rats. Respirology 2010;15:659-68.

81. Behringer A, Trappiel M, Berghausen EM, et al. Pioglitazone alleviates cardiac and vascular remodelling and improves survival in monocrotaline induced pulmonary arterial hypertension. Naunyn Schmiedebergs Arch Pharmacol 2016;389:369-79.

82. Schermuly RT, Dony E, Ghofrani HA, et al. Reversal of experimental pulmonary hypertension by PDGF inhibition. J Clin Invest 2005;115:2811-21.

83. Crnkovic S, Egemnazarov B, Damico R, et al. Disconnect between fibrotic response and right ventricular dysfunction. Am J Respir Crit Care Med 2019;199:1550-60.

84. Zhao L, Chen CN, Hajji N, et al. Histone deacetylation inhibition in pulmonary hypertension: Therapeutic potential of valproic acid and suberoylanilide hydroxamic acid. Circulation 2012;126:455-67.

85. Cavasin MA, Demos-Davies K, Horn TR, et al. Selective class i histone deacetylase inhibition suppresses hypoxiainduced cardiopulmonary remodeling through an antiproliferative mechanism. Circ Res 2012;110:739-48.

86. Bogaard HJ, Mizuno S, Al Hussaini AA, et al. Suppression of histone deacetylases worsens right ventricular dysfunction after pulmonary artery banding in rats. Am J Respir Crit Care Med 2011;183:1402-10.

87. Chen F, Li X, Aquadro E, et al. Inhibition of histone deacetylase reduces transcription of NADPH oxidases and ROS production and ameliorates pulmonary arterial hypertension. Free Radic Biol Med 2016;99:167-78.

88. De Raaf MA, Al Hussaini A, Gomez-Arroyo J, et al. Histone deacetylase inhibition with trichostatin A does not reverse severe angioproliferative pulmonary hypertension in rats (2013 Grover Conference series). Pulm Circ 2014;4:237-43.

89. Boucherat O, Chabot S, Paulin R, et al. HDAC6: A Novel
Histone Deacetylase Implicated in Pulmonary Arterial Hypertension. Sci Rep 2017;7:4546.

90. Soliman OII, Akin S, Muslem R, et al. Derivation and validation of a novel right-sided heart failure model after implantation of continuous flow left ventricular assist devices. Circulation 2018;137:891-906.

91. Hamdan R, Mansour H, Nassar P, et al. Prevention of Right Heart Failure After Left Ventricular Assist Device Implantation by Phosphodiesterase 5 Inhibitor. Artif Organs 2014;38:963-7.

92. Kerbaul F, Rondelet B, Demester JP, et al. Effects of levosimendan versus dobutamine on pressure load-induced right ventricular failure. Crit Care Med 2006;34:2814-9.

93. Nootens M, Kaufmann E, Rector T, et al. Neurohormonal activation in patients with right ventricular failure from pulmonary hypertension: Relation to hemodynamic variables and endothelin levels. J Am Coll Cardiol 1995;26:1581-5.

94. Grinnan D, Bogaard HJ, Grizzard J, et al. Treatment of group I pulmonary arterial hypertension with carvedilol is safe. Am J Respir Crit Care Med 2014;189:1562-4.

95. Cowley PM, Wang G, Chang AN, et al. The $\alpha 1 \mathrm{~A}-$ adrenergic receptor subtype mediates increased contraction of failing right ventricular myocardium. Am J Physiol Heart Circ Physiol 2015;309:H888-96.

96. Dai H, Jiang L, Xiao Z, et al. ACE2-angiotensin-(1-7)-Mas axis might be a promising therapeutic target for pulmonary arterial hypertension. Nat Rev Cardiol 2015;12:374.

97. Spiekerkoetter E, Kawut SM, de Jesus Perez VA. New and Emerging Therapies for Pulmonary Arterial Hypertension. Annu Rev Med 2019;70:45-59.

98. Patel VB, Zhong JC, Grant MB, et al. Role of the ACE2/ angiotensin 1-7 axis of the renin-angiotensin system in heart failure. Circ Res 2016;118:1313-26.

99. Khan A, Benthin C, Zeno B, et al. A pilot clinical trial of recombinant human angiotensin-converting enzyme 2 in acute respiratory distress syndrome. Crit Care 2017;21:234.

100. Nicin L, Abplanalp WT, Mellentin H, et al. Cell typespecific expression of the putative SARS-CoV-2 receptor ACE2 in human hearts. Eur Heart J 2020;41:1804-6.

101. Bertero E, Maack C. Metabolic remodelling in heart failure. Nat Rev Cardiol 2018;15:457-70.

102. Ritterhoff J, Tian R. Metabolismin cardiomyopathy: Every substrate matters. Cardiovasc Res 2017;113:411-21.

103. Ohira H, deKemp R, Pena E, et al. Shifts in myocardial fatty acid and glucose metabolism in pulmonary arterial hypertension: a potential mechanism for a maladaptive 
right ventricular response. Eur Heart J Cardiovasc Imaging 2016;17:1424-31.

104.Archer SL, Fang YH, Ryan JJ, et al. Metabolism and bioenergetics in the right ventricle and pulmonary vasculature in pulmonary hypertension. Pulm Circ 2013;3:144-52.

105. Tuunanen H, Engblom E, Naum A, et al. Trimetazidine, a metabolic modulator, has cardiac and extracardiac benefits in idiopathic dilated cardiomyopathy. Circulation 2008;118:1250-8.

106. Gao D, Ning N, Niu X, et al. Trimetazidine: A metaanalysis of randomised controlled trials in heart failure. Heart 2011;97:278-86.

107. Sossalla S, Maier LS. Role of ranolazine in angina, heart failure, arrhythmias, and diabetes. Pharmacol Ther 2012;133:311-23.

108.Zhang L, Lu Y, Jiang H, et al. Additional use of trimetazidine in patients with chronic heart failure: A meta-analysis. J Am Coll Cardiol 2012;59:913-22.

109.Liles JT, Hoyer K, Oliver J, et al. Ranolazine reduces remodeling of the right ventricle and provoked arrhythmias in rats with pulmonary hypertensions. J Pharmacol Exp Ther 2015;353:480-9.

110.Sommer N, Ghofrani HA, Pak O, et al. Current and future treatments of pulmonary arterial hypertension. $\mathrm{Br}$ J Pharmacol. 2020. [Epub ahead of print]. doi:10.1111/ bph.15016.

111. Maron BA, Leopold JA, Hemnes AR. Metabolic syndrome, neurohumoral modulation, and pulmonary arterial hypertension. Br J Pharmacol 2020;177:1457-71.

112. Wai T, García-Prieto J, Baker MJ, et al. Imbalanced OPA1 processing and mitochondrial fragmentation cause heart failure in mice. Science 2015;350:aad0116.

113.Hansmann G, Calvier L, Risbano MG, et al. Activation of the metabolic master regulator PPARg: A potential pioneering therapy for pulmonary arterial hypertension. Am J Respir Cell Mol Biol 2020;62:143-56.

114. Soccio RE, Chen ER, Rajapurkar SR, et al. Genetic Variation Determines PPAR $\gamma$ Function and Anti-diabetic Drug Response in Vivo. Cell 2015;162:33-44.

115.Kernan WN, Viscoli CM, Furie KL, et al. Pioglitazone after ischemic stroke or Transient Ischemic attack. N Engl J Med 2016;374:1321-31.

116.Hansmann G, De Jesus Perez VA, Alastalo TP, et al. An antiproliferative BMP-2/PPAR $\gamma / \mathrm{apoE}$ axis in human and murine SMCs and its role in pulmonary hypertension. J Clin Invest 2008;118:1846-57.

117. Crossno JT, Garat CV, Reusch JEB, et al. Rosiglitazone attenuates hypoxia-induced pulmonary arterial remodeling. Am J Physiol Lung Cell Mol Physiol 2007;292:L885-97.

118. Agard C, Rolli-Derkinderen M, Dumas-de-La-Roque E, et al. Protective role of the antidiabetic drug metformin against chronic experimental pulmonary hypertension. $\mathrm{Br}$ J Pharmacol 2009;158:1285-94.

119. Dean A, Nilsen M, Loughlin L, et al. Metformin Reverses Development of Pulmonary Hypertension via Aromatase Inhibition. Hypertension 2016;68:446-54.

120. Everett BM, Cornel JH, Lainscak M, et al. Antiinflammatory therapy with canakinumab for the prevention of hospitalization for heart failure. Circulation 2019;139:1289-99.

121. Humbert M, Monti G, Brenot F, et al. Increased interleukin-1 and interleukin-6 serum concentrations in severe primary pulmonary hypertension. Am J Respir Crit Care Med 1995;151:1628-31.

122. Quarck R, Nawrot T, Meyns B, et al. C-Reactive Protein. A New Predictor of Adverse Outcome in Pulmonary Arterial Hypertension. J Am Coll Cardiol 2009;53:1211-8.

123. Soon E, Holmes AM, Treacy CM, et al. Elevated levels of inflammatory cytokines predict survival in idiopathic and familial pulmonary arterial hypertension. Circulation 2010;122:920-7.

124. Cracowski JL, Chabot F, Labarère J, et al. Proinflammatory cytokine levels are linked to death in pulmonary arterial hypertension. Eur Respir J 2014;43:915-7.

125. Sydykov A, Mamazhakypov A, Petrovic A, et al. Inflammatory mediators drive adverse right ventricular remodeling and dysfunction and serve as potential biomarkers. Front Physiol 2018;9:609.

126. Dewachter L, Dewachter C. Inflammation in right ventricular failure: Does it matter? Front Physiol 2018;9:1056.

127.Dick SA, Epelman S. Chronic Heart Failure and Inflammation: What Do We Really Know? Circ Res 2016;119:159-76.

128. Bacmeister L, Schwarzl M, Warnke S, et al. Inflammation and fibrosis in murine models of heart failure. Basic Res Cardiol 2019;114:19.

129. Boehm M, Novoyatleva T, Kojonazarov B, et al. Nitric oxide synthase 2 induction promotes right ventricular fibrosis. Am J Respir Cell Mol Biol 2019;60:346-56.

130.Luitel H, Sydykov A, Schymura Y, et al. Pressure overload leads to an increased accumulation and activity of mast cells in the right ventricle. Physiol Rep 2017;5:e13146.

131. Bujak M, Frangogiannis NG. The role of IL-1 in the pathogenesis of heart disease. Arch Immunol Ther Exp 
(Warsz) 2009;57:165-76.

132. Saxena A, Chen W, Su Y, et al. IL-1 Induces

Proinflammatory Leukocyte Infiltration and Regulates Fibroblast Phenotype in the Infarcted Myocardium. J Immunol 2013;191:4838-48.

133. Mia MM, Boersema M, Bank RA. Interleukin-1 $\beta$ attenuates myofibroblast formation and extracellular matrix production in dermal and lung fibroblasts exposed to transforming growth factor- $\beta 1$. PLoS One 2014;9:e91559.

134. Nussbaum C, Klinke A, Adam M, et al. Myeloperoxidase: A leukocyte-derived protagonist of inflammation and cardiovascular disease. Antioxid. Redox Signal 2013;18:692-713.

135. Yet SF, Perrella MA, Layne MD, et al. Hypoxia induces severe right ventricular dilatation and infarction in heine oxygenase-1 null mice. J Clin Invest 1999;103:R23-9.

136. Bogaard HJ, Natarajan R, Henderson SC, et al. Chronic pulmonary artery pressure elevation is insufficient to explain right heart failure. Circulation 2009;120:1951-60.

137. Cole MP, Rudolph TK, Khoo NKH, et al. Nitro-fatty acid inhibition of neointima formation after endoluminal vessel injury. Circ Res 2009;105:965-72.

138. Masullo M, Pizza C, Piacente S. Oleanane derivatives for pharmaceutical use: a patent review (2000-2016). Expert Opin Ther Pat 2017;27:237-55.

139.Xie M, Burchfield JS, Hill JA. Pathological Ventricular Remodeling. Circulation 2013;128:1021-30.

140.Egemnazarov B, Crnkovic S, Nagy BM, et al. Right ventricular fibrosis and dysfunction: Actual concepts and common misconceptions. Matrix Biol 2018;68-69:507-21.

141.Janssen W, Schymura Y, Novoyatleva T, et al. 5-HT2B receptor antagonists inhibit fibrosis and protect from RV heart failure. Biomed Res Int 2015;2015:438403.

142. Boehm M, Tian X, Mao Y, et al. Delineating the molecular and histological events that govern right ventricular recovery using a novel mouse model of PA de-banding. Cardiovasc Res 2020;116:1700-9.

143.Zelt JGE, Chaudhary KR, Cadete VJ, et al. Medical Therapy for Heart Failure Associated with Pulmonary Hypertension. Circ Res 2019;124:1551-67.

144. Prins KW, Thenappan T, Weir EK, et al. Repurposing medications for treatment of pulmonary arterial hypertension: What's old is new again. J Am Heart Assoc 2019;8:e011343.

145. Groeneveldt JA, De Man FS, Westerhof BE. The right treatment for the right ventricle. Curr Opin Pulm Med 2019;25:410-7.

146. Tello K, Seeger W, Naeije R, et al. Right heart failure in pulmonary hypertension: Diagnosis and new perspectives on vascular and direct right ventricular treatment. Br J Pharmacol 2019. [Epub ahead of print]. doi: 10.1111/ bph.14866.

147.Xaymardan M, Tang L, Zagreda L, et al. Platelet-derived growth factor- $\mathrm{AB}$ promotes the generation of adult bone marrow-derived cardiac myocytes. Circ Res 2004;94:E3945.

148. Chintalgattu V, Ai D, Langley RR, et al. Cardiomyocyte PDGFR- $\beta$ signaling is an essential component of the mouse cardiac response to load-induced stress. J Clin Invest 2010;120:472-84.

149.Hopper RK, Moonen JRAJ, Diebold I, et al. In pulmonary arterial hypertension, reduced bmpr 2 promotes endothelial-to-Mesenchymal transition via hmga1 and its target slug. Circulation 2016;133:1783-94.

150. Calvier L, Chouvarine P, Legchenko E, et al. PPAR $\gamma$ Links BMP2 and TGF 1 Pathways in Vascular Smooth Muscle Cells, Regulating Cell Proliferation and Glucose Metabolism. Cell Metab 2017;25:1118-1134.e7.

151.Spiekerkoetter E, Tian X, Cai J, et al. FK506 activates BMPR2, rescues endothelial dysfunction, and reverses pulmonary hypertension. J Clin Invest 2013;123:3600-13.

152. Spiekerkoetter E, Sung YK, Sudheendra D, et al. Lowdose FK506 (Tacrolimus) in end-stage pulmonary arterial hypertension. Am J Respir Crit Care Med 2015;192:254-7.

153. Calvier L, Chouvarine P, Legchenko E, et al. Transforming growth factor $\beta 1$-and bone morphogenetic protein 2/ PPAR $\gamma$-regulated MicroRNAs in pulmonary arterial hypertension. Am J Respir Crit Care Med 2017;196:12278.

154. Yung LM, Yang P, Joshi S, et al. ACTRIIA-Fc rebalances activin/GDF versus BMP signaling in pulmonary hypertension. Sci Transl Med 2020;12:eaaz5660.

155. Rothman AMK, Arnold ND, Pickworth JA, et al. MicroRNA-140-5p and SMURF1 regulate pulmonary arterial hypertension. J Clin Invest 2016;126:2495-508.

156. Frump AL, Goss KN, Vayl A, et al. Estradiol improves right ventricular function in rats with severe angioproliferative pulmonary hypertension: Effects of endogenous and exogenous sex hormones. Am J Physiol Lung Cell Mol Physiol 2015;308:L873-90.

157.Piao L, Fang YH, Parikh K, et al. Cardiac glutaminolysis: A maladaptive cancer metabolism pathway in the right ventricle in pulmonary hypertension. J Mol Med 2013;91:1185-97.

158.Potus F, Ruffenach G, Dahou A, et al. Downregulation of MicroRNA-126 Contributes to the Failing Right 
Ventricle in Pulmonary Arterial Hypertension. Circulation 2015;132:932-43.

159. Suen CM, Stewart DJ, Montroy J, et al. Regenerative cell therapy for pulmonary arterial hypertension in animal models: a systematic review. Stem Cell Res Ther 2019;10:75.

160. Eschenhagen T, Bolli R, Braun T, et al. Cardiomyocyte regeneration: A consensus statement. Circulation 2017;136:680-6.

161. Trac D, Maxwell JT, Brown ME, et al. Aggregation of child cardiac progenitor cells into spheres activates notch signaling and improves treatment of right ventricular heart failure. Circ Res 2019;124:526-38.

162. Wehman B, Pietris N, Bigham G, et al. Cardiac Progenitor Cells Enhance Neonatal Right Ventricular Function After Pulmonary Artery Banding. Ann Thorac Surg 2017;104:2045-53.

163. Chery J, Huang S, Gong L, et al. Human neonatal thymus mesenchymal stem/stromal cells and chronic right ventricle pressure overload. Bioengineering 2019;6:15.

164.Liufu R, Shi G, He X, et al. The therapeutic impact of human neonatal BMSC in a right ventricular pressure overload model in mice. Stem Cell Res Ther 2020;11:96.

165. Ishigami S, Ohtsuki S, Tarui S, et al. Intracoronary autologous cardiac progenitor cell transfer in patients with hypoplastic left heart syndrome: The TICAP Prospective Phase 1 Controlled Trial. Circ Res 2015;116:653-64.

166. Ishigami S, Ohtsuki S, Eitoku T, et al. Intracoronary cardiac progenitor cells in single ventricle physiology: the perseus (cardiac progenitor cell infusion to treat univentricular heart disease) randomized phase 2 trial. Circ Res 2017;120:1162-73.

167.Hogan SE, Salazar MPR, Cheadle J, et al. Mesenchymal stromal cell-derived exosomes improve mitochondrial health in pulmonary arterial hypertension. Am J Physiol Lung Cell Mol Physiol 2019;316:L723-37.

168. Klinger JR, Pereira M, Del Tatto M, et al. Mesenchymal Stem Cell Extracellular Vesicles Reverse Sugen/Hypoxia Pulmonary Hypertension in Rats. Am J Respir Cell Mol Biol 2020;62:577-87.

169.Zhang S, Liu X, Ge LL, et al. Mesenchymal stromal cell-derived exosomes improve pulmonary hypertension through inhibition of pulmonary vascular remodeling. Respir Res 2020;21:71.

170.Willis GR, Fernandez-Gonzalez A, Anastas J, et al. Mesenchymal stromal cell exosomes ameliorate experimental bronchopulmonary dysplasia and restore lung function through macrophage immunomodulation.
Am J Respir Crit Care Med 2018;197:104-16.

171.Kreutzer FP, Fiedler J, Thum T. Non-coding RNAs: key players in cardiac disease. J Physiol 2020;598:2995-3003.

172.Jaé N, Dimmeler S. Noncoding RNAs in Vascular Diseases. Circ Res 2020;126:1127-45.

173.Huang CK, Kafert-Kasting S, Thum T. Preclinical and Clinical Development of Noncoding RNA Therapeutics for Cardiovascular Disease. Circ Res 2020;126:663-78.

174. Frump AL, Bonnet S, de Jesus Perez VA, et al. Emerging role of angiogenesis in adaptive and maladaptive right ventricular remodeling in pulmonary hypertension. Am J Physiol Lung Cell Mol Physiol 2018;314:L443-60.

175.Lahm T, Douglas IS, Archer SL, et al. Assessment of right ventricular function in the research setting: Knowledge gaps and pathways forward an official American thoracic society research statement. Am J Respir Crit Care Med 2018;198:e15-43.

176. Di Salvo TG, Guo Y, Su YR, et al. Right ventricular long noncoding RNA expression in human heart failure. Pulm Circ 2015;5:135-61.

177. Batkai S, Bär C, Thum T. MicroRNAs in right ventricular remodelling. Cardiovasc Res 2017;113:1433-40.

178. Cao Y, Yang Y, Wang L, et al. Analyses of long non-coding RNA and mRNA profiles in right ventricle myocardium of acute right heart failure in pulmonary arterial hypertension rats. Biomed Pharmacother 2018;106:1108-15.

179. Chun HJ, Bonnet S, Chan SY. Translational advances in the field of pulmonary hypertension: Translating MicroRNA biology in pulmonary hypertension: It will take more than "miR" words. Am J Respir Crit Care Med 2017;195:167-78.

180. Mehta J, Parthasarathy PT, Lockey R, et al. New hope for a microRNA therapy for pulmonary arterial hypertension. Front Genet 2013;4:137.

181. Meloche J, Paulin R, Provencher S, et al. Therapeutic Potential of microRNA Modulation in Pulmonary Arterial Hypertension. Curr Vasc Pharmacol 2015;13:331-40.

182. Courboulin A, Ranchoux B, Cohen-Kaminsky S, et al. MicroRNA networks in pulmonary arterial hypertension: Share mechanisms with cancer? Curr Opin Oncol 2016;28:72-82.

183. Carregal-Romero S, Fadón L, Berra E, et al. MicroRNA nanotherapeutics for lung targeting. Insights into pulmonary hypertension. Int J Mol Sci 2020;21:3253.

184.Paulin R, Sutendra G, Gurtu V, et al. A miR-208-Mef2 axis drives the decompensation of right ventricular function in pulmonary hypertension. Circ Res 2015;116:56-69.

185. Shi L, Kojonazarov B, Elgheznawy A, et al. MiR-223- 
IGF-IR signalling in hypoxia- and load-induced rightventricular failure: A novel therapeutic approach.

Cardiovasc Res 2016;111:184-93.

186. Omura J, Habbout K, Shimauchi T, et al. Identification of The Long Non-Coding RNA H19 as a New Biomarker and Therapeutic Target in Right Ventricular Failure in Pulmonary Arterial Hypertension. Circulation 2020;142:1464-84.

187. Viereck J, Bührke A, Foinquinos A, et al. Targeting muscleenriched long non-coding RNA H19 reverses pathological cardiac hypertrophy. Eur Heart J 2020;41:3462-74.

188. Velez-Roa S, Ciarka A, Najem B, et al. Increased sympathetic nerve activity in pulmonary artery hypertension. Circulation 2004;110:1308-12.

189. Ciarka A, Doan V, Velez-Roa S, et al. Prognostic significance of sympathetic nervous system activation in pulmonary arterial hypertension. Am J Respir Crit Care Med 2010;181:1269-75.

190. Esler M, Willett I, Leonard P, et al. Plasma noradrenaline kinetics in humans. J Auton Nerv Syst 1984;11:125-44.

191.de Man FS, Handoko ML, Guignabert C, et al. Neurohormonal axis in patients with pulmonary arterial hypertension: Friend or foe? Am J Respir Crit Care Med 2013;187:14-9.

192. Thenappan T, Roy SS, Duval S, et al. $\beta$-Blocker therapy is not associated with adverse outcomes in patients with pulmonary arterial hypertension A propensity score analysis. Circ Heart Fail 2014;7:903-10.

193. Bandyopadhyay D, Bajaj NS, Zein J, et al. Outcomes of -blocker use in pulmonary arterial hypertension: A propensity-matched analysis. Eur Respir J 2015;46:750-60.

194. Townsend RR, Mahfoud F, Kandzari DE, et al. Catheterbased renal denervation in patients with uncontrolled hypertension in the absence of antihypertensive medications (SPYRAL HTN-OFF MED): a randomised, sham-controlled, proof-of-concept trial. Lancet 2017;390:2160-70.

195.Azizi M, Schmieder RE, Mahfoud F, et al. Endovascular ultrasound renal denervation to treat hypertension (RADIANCE-HTN SOLO): a multicentre, international, single-blind, randomised, sham-controlled trial. Lancet 2018;391:2335-45.

196. Kandzari DE, Böhm M, Mahfoud F, et al. Effect of renal denervation on blood pressure in the presence of antihypertensive drugs: 6-month efficacy and safety results from the SPYRAL HTN-ON MED proof-of-concept randomised trial. Lancet 2018;391:2346-55.

197.Rothman A, Jonas M, Castel D, et al. Pulmonary Artery
Denervation Using Catheter-based Ultrasonic Energy.

EuroIntervention 2019;15:722-30.

198. Chen SL, Zhang YJ, Zhou L, et al. Percutaneous pulmonary artery denervation completely abolishes experimental pulmonary arterial hypertension in vivo. EuroIntervention 2013;9:269-76.

199. Rothman AMK, Arnold ND, Chang W, et al. Pulmonary Artery Denervation Reduces Pulmonary Artery Pressure and Induces Histological Changes in an Acute Porcine Model of Pulmonary Hypertension. Circ Cardiovasc Interv 2015;8:e002569.

200.Zhou L, Zhang J, Jiang XM, et al. Pulmonary Artery Denervation Attenuates Pulmonary Arterial Remodeling in Dogs with Pulmonary Arterial Hypertension Induced by Dehydrogenized Monocrotaline. JACC Cardiovasc Interv 2015;8:2013-23.

201. Chen SL, Zhang FF, Xu J, et al. Pulmonary artery denervation to treat pulmonary arterial hypertension: The single-center, prospective, first-in-man padn-1 study (first-in-man pulmonary artery denervation for treatment of pulmonary artery hypertension). J Am Coll Cardiol 2013;62:1092-100.

202. Chen SL, Zhang H, Xie DJ, et al. Hemodynamic, functional, and clinical responses to pulmonary artery denervation in patients with pulmonary arterial hypertension of different causes: phase II results from the Pulmonary Artery Denervation-1 study. Circ Cardiovasc Interv 2015;8:e002837.

203.Zhang H, Zhang J, Chen M, et al., Pulmonary Artery Denervation Significantly Increases 6-minute Walk Distance for Patients with Combined Pre- and Postcapillary Pulmonary Hypertension Associated with the Left Heart Failure: PADN-5 Study. JACC Cardiovasc Interv 2019;12:274-84.

204. Galiè N, Humbert M, Vachiery JL, et al. 2015 ESC/ERS Guidelines for the diagnosis and treatment of pulmonary hypertension: The Joint Task Force for the Diagnosis and Treatment of Pulmonary Hypertension of the European Society of Cardiology (ESC) and the European Respiratory Society (ERS): Endorsed by: Association for European Paediatric and Congenital Cardiology (AEPC), International Society for Heart and Lung Transplantation (ISHLT). Eur Heart J 2016;37:67-119.

205. Rothman AMK, Vachiery JL, Howard LS, et al. Intravascular Ultrasound Pulmonary Artery Denervation to Treat Pulmonary Arterial Hypertension (TROPHY1): Multicenter, Early Feasibility Study. JACC Cardiovasc Interv 2020;13:989-99. 
206. Mathai SC, Puhan MA, Lam D, et al. The minimal important difference in the 6-minute walk test for patients with pulmonary arterial hypertension. Am J Respir Crit Care Med 2012;186:428-33.

207. Napp LC, Bauersachs J. Triple Cannulation ECMO. IntechOpen, 2016. doi: 10.5772/63392.

208. Anderson MB, Goldstein J, Milano C, et al. Benefits of a novel percutaneous ventricular assist device for right heart failure: The prospective RECOVER RIGHT study of the Impella RP device. J Heart Lung Transplant 2015;34:154960.

209. Kapur NK, Paruchuri V, Jagannathan A, et al. Mechanical circulatory support for right ventricular failure. JACC Heart Fail 2013;1:127-34.

210. Truby L, Naka Y, Kalesan B, et al. Important role of mechanical circulatory support in acute myocardial infarction complicated by cardiogenic shock. Eur J Cardiothorac Surg 2015;48:322-8.

Cite this article as: Klinke A, Schubert T, Müller M, Legchenko E, Zelt JGE, Shimauchi T, Napp LC, Rothman AMK, Bonnet S, Stewart DJ, Hansmann G, Rudolph V. Emerging therapies for right ventricular dysfunction and failure. Cardiovasc Diagn Ther 2020;10(5):1735-1767. doi: 10.21037/cdt20-592
211.John R, Long JW, Massey HT, et al. Outcomes of a multicenter trial of the Levitronix CentriMag ventricular assist system for short-term circulatory support. J Thorac Cardiovasc Surg 2011;141:932-9.

212. Maynes EJ, O’Malley TJ, Luc JGY, et al. Comparison of SynCardia total artificial heart and HeartWare HVAD biventricular support for management of biventricular heart failure: a systematic review and meta-analysis. Ann Cardiothorac Surg 2020;9:69-80.

213. Lavee J, Mulzer J, Krabatsch T, et al. An international multicenter experience of biventricular support with HeartMate 3 ventricular assist systems J Heart Lung Transplant 2018;37:1399-402.

214.Arabía FA, Cantor RS, Koehl DA, et al. Interagency registry for mechanically assisted circulatory support report on the total artificial heart. J Heart Lung Transplant 2018;37:1304-12. 